\title{
THE
}

\section{What atmospheric oxygen measurements can tell us about the global carbon cycle}

\author{
Ralph F. Keeling \\ Raymond P. Najjar \\ Michael L. Bender \\ University of Rhode Island \\ Pieter P. Tans \\ University of Rhode Island
}

Follow this and additional works at: https://digitalcommons.uri.edu/gsofacpubs

Terms of Use

All rights reserved under copyright.

\section{Citation/Publisher Attribution}

Keeling, R. F., Najjar, R. P., Bender, M. L., \& Tans, P. P. (1993). What atmospheric oxygen measurements can tell us about the global carbon cycle. Global Biogeochemical Cycles, 7(1), 37-67. doi:10.1029/92GB02733 Available at: https://doi.org/10.1029/92GB02733

This Article is brought to you for free and open access by the Graduate School of Oceanography at DigitalCommons@URI. It has been accepted for inclusion in Graduate School of Oceanography Faculty Publications by an authorized administrator of DigitalCommons@URI. For more information, please contact digitalcommons-group@uri.edu. 
WHAT ATMOSPHERIC OXYGEN MEASUREMENTS CAN TELL US ABOUT THE GLOBAL CARBON CYCLE

Ralph F. Keeling and Raymond P. Najjar

National Center for Atmospheric Research, Boulder, Colorado

Michael L. Bender

Graduate School of Oceanography, University of Rhode Island, Kingston, Rhode Island

Pieter P. Tans

Climate Monitoring and Diagnostics Laboratory, National oceanic and Atmospheric Administration, Boulder, Colorado

Abstract. This paper explores the role that measurements of changes in atmospheric oxygen, detected through changes in the $\mathrm{O}_{2} / \mathrm{N}_{2}$ ratio of air, can play in improving our understanding of the global carbon cycle. Simple conceptual models are presented in order to clarify the biological and physical controls on the exchanges of $\mathrm{O}_{2}$, $\mathrm{CO}_{2}, \mathrm{~N}_{2}$, and $\mathrm{Ar}$ across the air-sea interface and in order to clarify the relationships between biologically mediated fluxes of oxygen across the air-sea interface and the cycles of organic carbon in the ocean. Predictions of largescale seasonal variations and gradients in atmospheric oxygen are presented. A two-dimensional model is used to relate changes in the $\mathrm{O}_{2} / \mathrm{N}_{2}$ ratio of air to the sources of oxygen from terrestrial and marine

Copyright 1993

by the American Geophysical Union.

Page number $92 \mathrm{~GB} 02733$.

$0886-6236 / 93 / 92 \mathrm{~GB}-02733 \$ 10.00$ ecosystems, the thermal ingassing and outgassing of seawater, and the burning of fossil fuel. The analysis indicates that

measurements of seasonal variations in atmospheric oxygen can place new constraints on the large-scale marine biological productivity. Measurements of the north-south gradient and depletion rate of atmospheric oxygen can help determine the rates and geographical distribution of the net storage of carbon in terrestrial ecosystems.

\section{INTRODUCTION}

With recent developments it is now feasible to measure variations in the oxygen content of the atmosphere at the parts per million level. Regular measurements of changes in atmospheric $\mathrm{O}_{2}$ are currently being made at a number of locations around the world using two independent techniques, one based on interferometry [Keeling, 1988bi Keeling and Shertz, 1992] and 
one based on stable isotope mass spectroscopy (Bender, manuscript in preparation, 1992). The motivation for these programs is that oxygen measurements can inform us about fundamental aspects of the global carbon cycle. This paper explores the relation between the observable variations in atmospheric oxygen and the fluxes of carbon which control these variations so that the forthcoming oxygen data can be rapidly incorporated into the growing body of data on the global carbon cycle.

on time scales less than many thousands of years, variations in atmospheric $\mathrm{O}_{2}$ are controlled primarily by chemical reactions which produce or consume organic matter. Geochemically important reactions involving organic carbon include: (1) the photosynthesis and respiration by land biota, described schematically as

$$
\mathrm{CO}_{2}+\mathrm{H}_{2} \mathrm{O}-\mathrm{CH}_{2} \mathrm{O}+\mathrm{O}_{2}
$$

where $\mathrm{CH}_{2} \mathrm{O}$ represents the approximate composition of terrestrial organic matter (actually, the ratio of $\mathrm{O}_{2}$ production to $\mathrm{CO}_{2}$ consumption averages about 1.05 [Keeling, 1988]), (2) the photosynthesis and respiration of marine biota, described by

$$
\begin{array}{r}
106 \mathrm{CO}_{2}+16 \mathrm{NO}_{3}^{-}+\mathrm{H}_{2} \mathrm{PO}_{4}^{-}+17 \mathrm{H}^{+}-\overrightarrow{ } \\
\mathrm{C}_{106} \mathrm{H}_{263} \mathrm{O}_{110} \mathrm{~N}_{16} \mathrm{P}+138 \mathrm{O}_{2}
\end{array}
$$

where $\mathrm{C}_{106} \mathrm{H}_{263} \mathrm{O}_{110} \mathrm{~N}_{16} \mathrm{P}$ represents the approximate composition of marine organic matter [Redfield et al. 1963], and (3) the burning of fossil fuels, described by

$$
\mathrm{CH}_{\mathrm{y}}+\left(1+\frac{y}{4}\right) \mathrm{O}_{2} \rightarrow \frac{y}{2} \mathrm{H}_{2} \mathrm{O}+\mathrm{CO}_{2}
$$

where $\mathrm{CH}_{y}$ represents the average composition of fossil fuels. Through these reactions, sources of $\mathrm{O}_{2}$ are stoichiometrically linked to sinks of $\mathrm{CO}_{2}$ and vice versa, although the $\mathrm{O}_{2}: C$ ratio depends somewhat on the composition of the organic matter. A summary of the oxygen cycle which emphasizes these links with organic carbon is shown in Figure 1.

While the above reactions are the dominant sources and sinks of $\mathrm{O}_{2}$, additional chemical reactions influence the abundance of atmospheric $\mathrm{CO}_{2}$. The geochemistry of $\mathrm{CO}_{2}$ differs qualitatively from that of $\mathrm{O}_{2}$ because $\mathrm{CO}_{2}$ reacts with water to form carbonic acid which, in turn, can react with basic compounds such as carbonate ions. As a result, the oceans are a major reservoir of $\mathrm{CO}_{2}$ but only a minor reservoir of $\mathrm{O}_{2}$ (see Figure 1 ). Also, the upper ocean equilibrates with respect to $\mathrm{O}_{2}$ on a time scale of a few weeks but equilibrates with respect to $\mathrm{CO}_{2}$ on a time scale of a year or more [Broecker and Peng, 1974; Broecker and Peng, 1982]. The different oceanic behavior of $\mathrm{O}_{2}$ and $\mathrm{CO}_{2}$ means that variations in $\mathrm{O}_{2}$ contain information on the global carbon cycle which is not contained in variations of $\mathrm{CO}_{2}$ alone.

One important application of $\mathrm{O}_{2}$ measurements will be to constrain rates of biological new production in the oceans on the basis of seasonal variations in atmospheric $\mathrm{O}_{2}$; another application will be to constrain sources and sinks of carbon from terrestrial ecosystems on the basis of interannual trends and gradients in atmospheric $\mathrm{O}_{2}$. These two applications are explored in more detail in the remainder of this paper.

Throughout this paper we express variations in atmospheric oxygen in terms of relative changes in the $\mathrm{O}_{2} / \mathrm{N}_{2}$ ratio. Thus we define

$$
\begin{aligned}
& \delta\left(\mathrm{O}_{2} / \mathrm{N}_{2}\right) \text { per meg }= \\
& \left(\frac{\left(\mathrm{O}_{2} / \mathrm{N}_{2}\right)_{\text {sample }}}{\left(\mathrm{O}_{2} / \mathrm{N}_{2}\right)_{\text {reference }}}-1\right) \cdot 10^{6}
\end{aligned}
$$




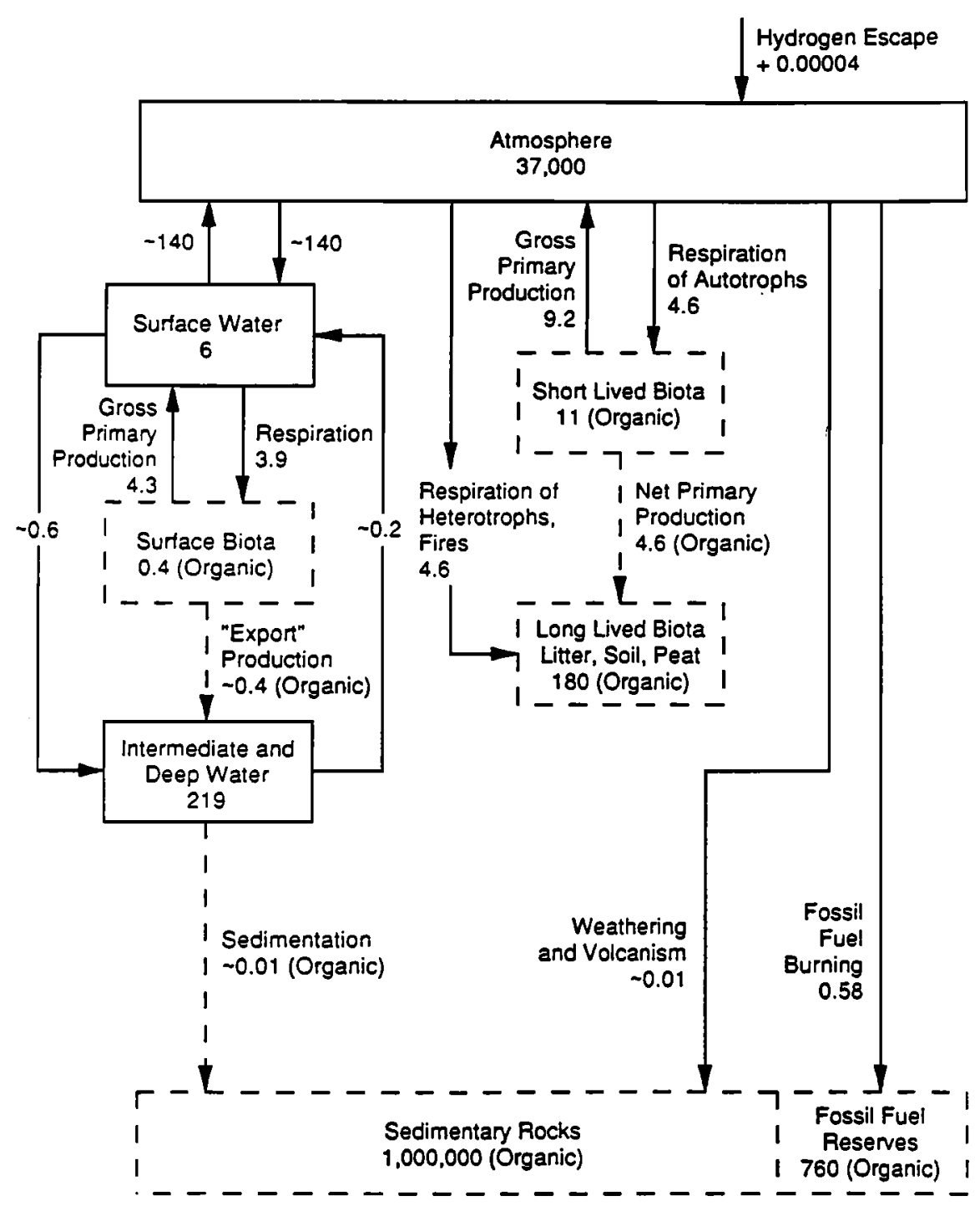

Fig. 1. Schematic representation of the global oxygen cycle showing short-term and long-term sources and sinks and coupling with the carbon cycle in units of $10^{15}$ moles and $10^{15}$ moles $\mathrm{yr}^{-1}$. Oxygen fluxes and reservoirs are denoted by solid lines and solid boxes, respectively. Organic fluxes and reservoirs are denoted by dashed lines and dashed boxes, respectively. organic matter is expressed in terms of $\mathrm{O}_{2}$ equivalent, i.e., the amount of $\mathrm{O}_{2}$ required to fully oxidize the material. organic reservoirs and fluxes are adapted from Bolin [1983] and may differ from values used for our subsequent calculations. Here "export" production refers to the net downward flux of organic carbon at the base of the seasonal thermocline. Advective fluxes of $\mathrm{O}_{2}$ in the ocean are consistent with a 1000-year turnover time for the intermediate and deepwater reservoir. Other fluxes are consistent with Keeling [1988a]. 
where the units "per meg" refer to a one millionth change in a ratio. In these units, 1/0.2095 $=4.8$ per meg is essentially equivalent to 1 ppmV because oxygen comprises $20.95 \%$ of air. By equivalent we mean, for example, that the conversion of 1 ppmV of $\mathrm{CO}_{2}$ into $\mathrm{O}_{2}$ would increase the $\mathrm{O}_{2} / \mathrm{N}_{2}$ ratio of the sample by 4.8 per meg. Note that we intentionally avoid mole fraction units for describing changes in atmospheric $\mathrm{O}_{2}$ concentration because the $\mathrm{O}_{2}$ mole fraction is sensitive to variations in trace gases (especially $\mathrm{CO}_{2}$ ) when these are included, as is normally the case, in the definition of whole air.

The remainder of this paper is organized as follows: Section 2 presents concepts needed to understand the controls on exchanges of $\mathrm{O}_{2}$ between the atmosphere and the ocean; section 3 presents estimates of the sources and sinks of atmospheric $\mathrm{O}_{2}$ from both marine and terrestrial processes and uses these to predict the atmospheric $\mathrm{O}_{2} / \mathrm{N}_{2}$ variations using a two-dimensional transport model; section 4 discusses application of atmospheric $\mathrm{O}_{2} / \mathrm{N}_{2}$ measurements for constraining oceanic new production and net carbon exchanges with terrestrial ecosystems.

\section{OCEANIC PROCESSES}

\subsection{Air-Sea Gas Exchange}

We begin with a simple conceptual model illustrating the controls on exchange of $\mathrm{CO}_{2}, \mathrm{O}_{2}, \mathrm{~N}_{2}$, and $\mathrm{Ar}$ across the air-sea interface. The model consists of a single wellmixed ocean box corresponding to a mixed layer with a constant depth of $80 \mathrm{~m}$ and a single well-mixed atmospheric box corresponding to the overlying atmospheric column. The mixed-layer concentration of a given species is governed by the equation

$$
H \frac{d C}{d t}=-F+H \frac{d P}{d t}
$$

where $H$ is the mixed layer depth in meters, $C$ is the mixed layer concentration in moles $\mathrm{m}^{-3}, F$ is the net flux from the mixed layer into the atmosphere in moles $\mathrm{m}^{-2}$ day ${ }^{-1}$, and $d P / d t$ is the biological source or sink of the species in moles $\mathrm{m}^{-3}$ day $^{-1}$ ( $P$ represents the number of moles which has been added to or removed from the mixed layer by biological activity since the beginning of the year in moles $\mathrm{m}^{-3}$ ). Air-sea gas exchange is

parameterized according to

$$
F=K\left(C-C_{\theta q}\right)
$$

where $K$ is the gas exchange velocity in meters per day and $C_{\theta q}$ is the concentration of $C$ in equilibrium with the atmosphere. Combining (5) and (6) and subtracting $H d C_{e q} / d t$ from both sides yields

$$
\frac{d\left(C-C_{e q}\right)}{d t}=-\frac{K}{H}\left(C-C_{e q}\right)+\frac{d P}{d t}-\frac{d C_{e q}}{d t}
$$

which shows that saturation anomalies are dissipated with an exchange time constant of $H / K$. The last two terms account for the effects of biological and thermal forcing, respectively. The latter term also includes the effects of changes in $C_{e q}$ due to changes in the atmospheric partial pressure of the species. In our analysis, however, we neglect this second-order effect by assuming that $C_{\theta q}$ varies only because of temperature variations in the water.

In order to apply the model to $\mathrm{CO}_{2}$, we must account for the reactions between dissolved $\mathrm{CO}_{2}$ and bicarbonate and carbonate ions. Mass balance requires that the sources and sinks of carbon dioxide from marine biological activity and air-sea exchange are matched by 
corresponding changes in total dissolved inorganic carbon (DIC), defined as the sum of dissolved $\mathrm{CO}_{2}$, bicarbonate, and carbonate. Mixedlayer DIC has a well defined equilibrium level with respect to atmospheric $\mathrm{CO}_{2}$ which depends on temperature, salinity, and alkalinity. It is therefore possible to express the air-sea exchange rate of $\mathrm{CO}_{2}$ directly in terms of the disequilibrium of DIC. writing (6) for $\mathrm{CO}_{2}$, we have

$$
F_{\mathrm{CO}_{2}}=K_{\mathrm{CO}_{2}}\left(\left[\mathrm{CO}_{2}\right]-\left[\mathrm{CO}_{2}\right]_{\ominus q}\right)
$$

For small deviations from equilibrium (appropriate over a seasonal cycle), this can be written

$$
\begin{aligned}
& F_{\mathrm{CO}_{2}}= \\
& K_{\mathrm{CO}_{2}}\left(\frac{\partial\left[\mathrm{CO}_{2}\right]}{\partial[D I C]}\right)_{[\mathrm{ALK}, \mathrm{T}}\left([D I C]-[D I C]_{\mathrm{Qg}}\right)
\end{aligned}
$$

where $[D I C]$ eq is the concentration of $D I C$ in equilibrium with atmospheric $\mathrm{CO}_{2}$ at the mixed layer temperature, salinity, and alkalinity. We can thus define an effective exchange constant for DIC given by

$$
K_{D I C}=K_{\mathrm{CO}_{2}}\left(\frac{\partial\left[\mathrm{CO}_{2}\right]}{\partial[D I C]}\right)_{[A L K], T}
$$

The magnitude of the thermodynamic partial derivative depends on the buffering capacity of seawater and is closely related to the Revelle Factor, $R$, where

$$
R=\frac{[D I C]}{\left[\mathrm{CO}_{2}\right]}\left(\frac{\partial\left[\mathrm{CO}_{2}\right]}{\partial[D I C]}\right)_{[A L K], T}
$$

(see, e.g., Broecker and Peng [1982]). Over a typical range of surface ocean conditions $\left(\partial\left[\mathrm{CO}_{2}\right] / \partial[D I C]\right)_{[A L K], T}$ varies from 0.05 to 0.08 . Accordingly, the reactions with bicarbonate and carbonate in seawater slow down the equilibration time for $\mathrm{CO}_{2}$ by about a factor of 12 to 20 compared to other gases. It is for this reason that, on short time scales, the exchange of atmospheric $\mathrm{CO}_{2}$ with the ocean is generally much less significant than the exchange of $\mathrm{O}_{2}$ [Broecker and Peng, 1982; Keeling and Shertz, 1992].

\subsection{Mixed-Layer Processes}

The driving forces for air-sea exchange of $\mathrm{CO}_{2}$ and $\mathrm{O}_{2}$ can be readily explored using the simple mixed-layer model developed above. To account for seasonal variations, we represent the biological and thermal forcing as simple sinusoidal functions

$$
C_{e q}=\alpha_{T} \sin \left(\omega t-\phi_{T}\right)+\bar{C}
$$

$$
P=\alpha_{P} \sin \left(\omega t-\phi_{P}\right)+\text { const }
$$

or equivalently

$$
\frac{d P}{d t}=\alpha_{P} \omega \cos \left(\omega t-\phi_{P}\right)
$$

where $\alpha_{P}$ and $\alpha_{T}$ represent the amplitudes of the biological and thermal forcing in mole $\mathrm{m}^{-3}, \overline{\mathrm{C}}$ is the annual-mean equilibrium concentration, $1 / \omega$ is (365 days) $/ 2 \pi$ $=66$ days, and $\phi_{P}$ and $\phi_{T}$ are the phase lags of the biological and thermal forcing relative to Jan. 1, respectively.

Equations (7) through (13) can be solved analytically. The solution for the mixed-layer concentration for biological or thermal forcing alone has the form where

$$
\left.C-C_{e q}=\frac{\omega H}{K} f \alpha \cos \left(\left(t-t_{1 a g}\right)-\Phi\right)\right)^{(15}
$$

where 


$$
f=\left(1+\left(\frac{\omega H}{K}\right)^{2}\right)^{-1 / 2} ; t_{1 a g}=\frac{1}{\omega} \tan ^{-1}\left(\frac{\omega H}{K}\right)
$$

where $\alpha$ and $\phi$ refer to the amplitude and phase of either the biological or the thermal forcing. The time-integrated air-sea flux, which is the same as the change in the atmospheric reservoir, has the form

$$
\int_{0}^{t} F d t^{\prime}=H f \bar{C} \alpha \sin \left(\omega\left(t-t_{1 a g}\right)-\phi\right)
$$

If both biological and thermal forcing are present, then the solution is simply given by the sum of solutions for biological and thermal forcing alone. The parameter $f$ is a measure of how efficiently the gas equilibrates with the atmosphere. For a rapidly equilibrating gas, $f$ approaches unity, while for a slowly equilibrating gas $f$ approaches zero. The term $t_{\text {lag }}$ (days) is a measure of the delay between maxima (or minima) of the forcing and the response.

The values taken for the biological and thermal forcing parameters are summarized in Table 1. These values were chosen to be representative for temperate waters. We assume that the sinusoidal form of the biological forcing takes account of the following processes: In the spring and summer, nutrients which were brought into the mixed layer by convection during the previous winter are consumed by photosynthesis, and this produces organic carbon which sinks and is oxidized in deeper waters. The net photosynthesis leads to the production of oxygen and consumption of carbon dioxide from the mixed layer. In the fall and winter, the rate of vertical mixing between the mixed layer and the deeper waters increases, and because the deeper waters are depleted in oxygen and enriched in inorganic carbon, the mixing removes oxygen and adds inorganic carbon to the mixed layer. Thus, although the model does not explicitly account for vertical. mixing between the mixed layer: and deeper waters, this mixing is implicitly included in the biological source/sink term.

We first consider the case in which temperature is constant and the only forcing is due to biological activities. The changes in $\mathrm{O}_{2}$ and $\mathrm{CO}_{2}$ in the atmosphere and mixed layer, for this case, are shown in Figure 2. Because air-sea exchange of $\mathrm{O}_{2}$ is efficient, changes in dissolved $\mathrm{O}_{2}$ closely follow the form of biological production with a lag of $t_{\text {lag }}=22$ days. This lag can be rationalized by noting that, when the biological source switches from positive to negative at the end of September, there is a residual supersaturation of $\mathrm{O}_{2}$ as a result of production which occurred over the previous few weeks, and this residual supersaturation continues to drive an $\mathrm{O}_{2}$ flux into the atmosphere. The changes in dissolved $\mathrm{O}_{2}$ reflect only a small fraction of the actual biological production, the bulk of which is exchanged into the atmosphere. The cycle in atmospheric $\mathrm{O}_{2}$ peaks 3 months $(1 / 4$ cycle) after the maximum in dissolved $\mathrm{O}_{2}$. The finite barrier to air-sea exchange for $\mathrm{O}_{2}$ has little impact on the amplitude of the cycle in atmospheric $\mathrm{O}_{2}$, which is only $7 \%$ smaller

( $1-f=0.07$ ) than what would be predicted assuming infinitely rapid air-sea exchange of $\mathrm{O}_{2}$. Thus, to a close approximation, the changes in atmospheric $\mathrm{O}_{2}$ reflect the timeintegral of the net biological source for $\mathrm{O}_{2}$. in the mixed layer. The finite barrier to air-sea exchange, however, has a significant impact on the phasing of the atmospheric $\mathrm{O}_{2}$ cycle, which lags by $t_{\text {lag }}=22$ days what would be 
TABLE 1. Model Forcing Parameters

\begin{tabular}{|c|c|c|c|c|}
\hline & DIC & $\mathrm{O}_{2}$ & $\mathrm{~N}_{2}$ & Ar \\
\hline Atmospheric mole fraction & 0.00034 & 0.2095 & 0.7808 & 0.00938 \\
\hline $\begin{array}{l}\bar{C} \text {, dissolution } \\
\text { concentration }(\mu \text { mole } / \mathrm{kg})^{b}\end{array}$ & 2077 & 248.5 & 453.0 & 12.5 \\
\hline $\begin{array}{l}\alpha_{T} \text {, thermal source } \\
(\mu \mathrm{mole} / \mathrm{kg})^{b}\end{array}$ & -17.0 & -9.9 & -16.2 & -0.483 \\
\hline $\begin{array}{l}\phi_{T}, \underset{\text { phase }}{\text { ph thermal }} \\
\text { source }\end{array}$ & 0 & 0 & 0 & 0 \\
\hline $\begin{array}{l}\alpha_{P}, \text { biological source } \\
(\mu \mathrm{mole} / \mathrm{kg})\end{array}$ & 22.0 & -28.6 & 0 & 0 \\
\hline $\begin{array}{l}\phi_{P}, \text { phase of biological } \\
\text { source }\end{array}$ & 0 & 0 & 0 & 0 \\
\hline Diffusivity $\left(10^{-5} \mathrm{~cm}^{2} / \mathrm{sec}\right)^{d}$ & 1.45 & 1.97 & 2.14 & 1.94 \\
\hline$K$, exchange Vel. (m/day) ${ }^{e}$ & 0.203 & 3.50 & 3.64 & 3.47 \\
\hline$H / K$, exchange time (days) ${ }^{f}$ & 395 & 22.9 & 22.0 & 23.1 \\
\hline$f$, fractional equil. ${ }^{g}$ & 0.144 & 0.928 & 0.933 & 0.929 \\
\hline$\tau_{\text {lag, }}$ lag time (days) ${ }^{g}$ & 82.7 & 21.8 & 21.0 & 22.0 \\
\hline $\begin{array}{l}\text { Amplitude of integrated } \\
\text { air-sea flux due to } \\
\pm 2 \text { C change (moles } \mathrm{m}^{-2} \text { ) }\end{array}$ & 0.196 & 0.738 & 1.211 & 0.0358 \\
\hline $\begin{array}{l}\text { Amplitude of integrated } \\
\text { air-sea flux due to } \\
\pm 22 \mu \text { mole } / \mathrm{kg} \text { biological } \\
\left.\text { uptake of DIC (moles } \mathrm{m}^{-2}\right)^{g}\end{array}$ & 0.253 & 2.69 & 0 & 0 \\
\hline
\end{tabular}

\footnotetext{
"From Keeling [1988a]. The value in the DIC column refers to atmospheric $\mathrm{CO}_{2}$ mole fraction.

Assumes that the mixed layer temperature has an annual range of 13 to $17^{\circ} \mathrm{C}$ with a maximum on Oct. 1 and a minimum on April 1 . Coefficients are calculated using solubility data for $\mathrm{O}_{2}, \mathrm{~N}_{2}$, and Ar from Weiss [1970], using data for DIC from Peng et al. [1987], assuming one atmosphere total pressure, a salinity of 34.5 per mil, and an alkalinity of $2330 \mu \mathrm{eq} / \mathrm{kg}$.

Assumes that $44 \mu$ mole $\mathrm{c} / \mathrm{kg}$ are removed between April 1 and sept. 31 and the same amount is replenished between Oct. 1 through Mar. 31. Assumes that alkalinity is constant throughout the year, and a assumes standard Redfield $\mathrm{O}_{2}: \mathrm{C}$ ratio of $1.30: 1$.

Data under DIC column is for $\mathrm{CO}_{2}$ from Jähne et al. [1987]. For $\mathrm{O}_{2}$, $\mathrm{N}_{2}$, and $\mathrm{Ar}$ the dara are from Wise and Houghton [1966].

'Calculated assuming an exchange velocity for $\mathrm{CO}_{2}$ of $3 \mathrm{~m} /$ day. Value for DIC is calculated by scaling by 0.0676 (see text); values for $\mathrm{O}_{2}, \mathrm{~N}_{2}$, and $\mathrm{Ar}$ are calculated by scaling the value for $\mathrm{CO}_{2}$ according to the square root of the diffusivity.

${ }^{\mathrm{f}}$ Assumes a mixed layer depth of $\mathrm{H}=80 \mathrm{~m}$.

${ }^{\mathrm{g}}$ Formulas are given in text.
} 

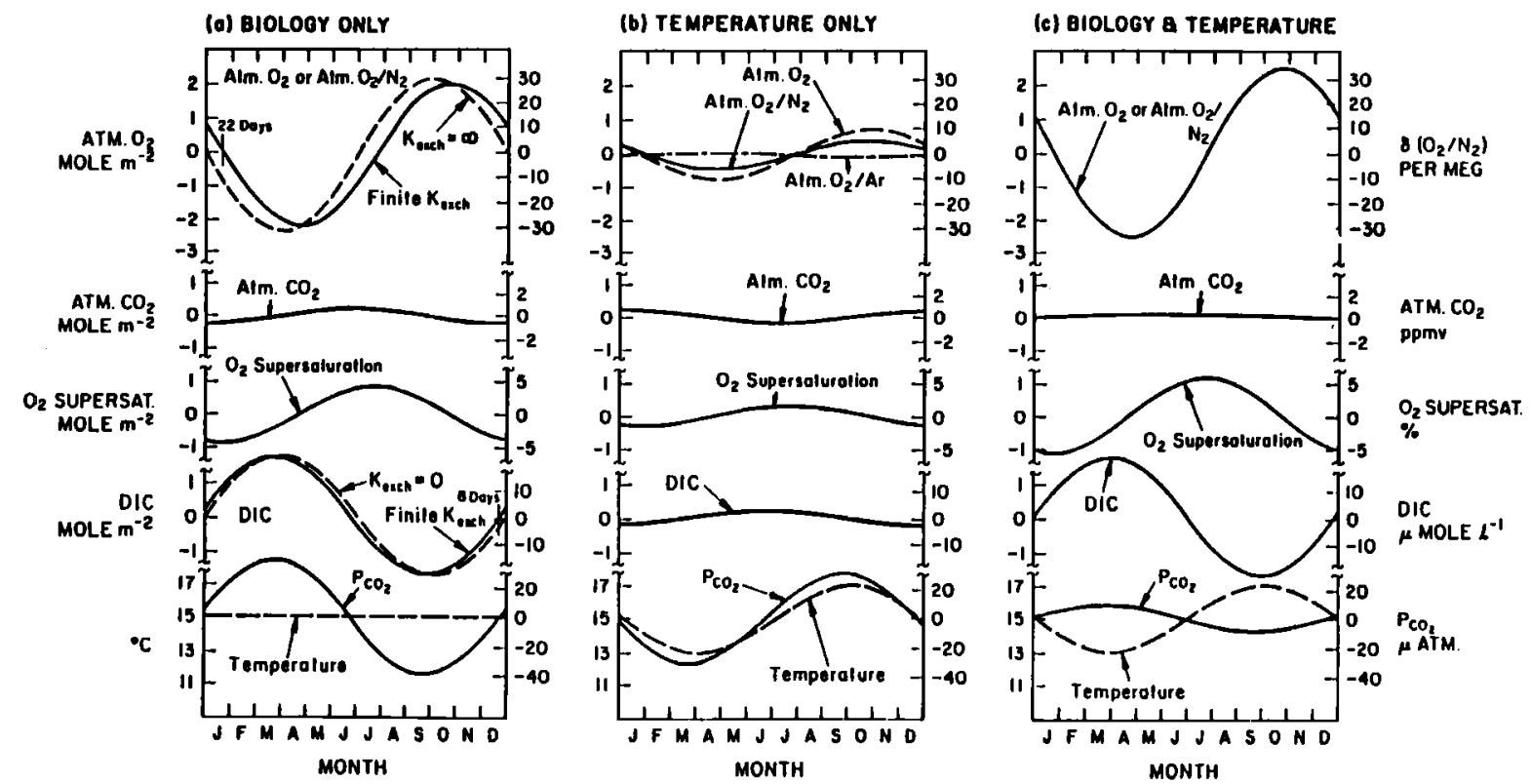

Fig. 2. Changes in the composition of the mixed layer and atmosphere in response to forcing by biological activity and temperature changes within the mixed-layer, based on a two-box model (see text) for the northern hemisphere. Shown are the changes in atmospheric $\mathrm{O}_{2}$, atmospheric $\mathrm{CO}_{2}$, dissolved $\mathrm{O}_{2}$, dissolved inorganic carbon (DIC), $\mathrm{CO}_{2}$ partial pressure in the mixed layer, and mixed-layer temperature. Dissolved $\mathrm{O}_{2}$ is expressed as a saturation anomaly. On the left axis, the compositional changes are given in units of moles per square meter of sea surface. One the right axis the changes are expressed in concentration units, for example, per meg, ppmv or $\mu$ mole $1^{-1}$. Forcing by marine biology only

predicted assuming infinitely rapid air-sea exchange of $\mathrm{O}_{2}$.

The changes in atmospheric $\mathrm{O}_{2}$ are mirrored by changes in DIC in the water which, because air-sea exchange of $\mathrm{CO}_{2}$ is very inefficient, also closely follow the time integral of the net biological production. The model indicates that the changes in DIC are (i.e., temperature constant). Shown are the effects on atmospheric $\mathrm{O}_{2}$ of assuming infinitely rapid air-sea exchange, and the effects on DIC of assuming infinitely slow air-sea exchange. With infinitely slow exchange, the changes in DIC simply reflect biological addition and removal of carbon, i.e. the changes reflect the term $P$ in Equation (13). Forcing by temperature only (i.e., no biology). Shown are the effects on atmospheric $\mathrm{O}_{2} / \mathrm{N}_{2}$ when only the $\mathrm{O}_{2}$ flux is included, the effect on $\mathrm{O}_{2} / \mathrm{N}_{2}$ when both the $\mathrm{O}_{2}$ and $\mathrm{N}_{2}$ flux are included, and the effect on $\mathrm{O}_{2} / \mathrm{Ar}$ when both the $\mathrm{O}_{2}$ and $\mathrm{Ar}$ flux are included. (C) Forcing by both marine biology and temperature.

scarcely different from what would be predicted assuming infinitely slow exchange for $\mathrm{CO}_{2}$. The principal effect of air-sea exchange of $\mathrm{CO}_{2}$ on DIC is to shift the phasing of the changes in DIC earlier by about 8 days relative to what is expected in the case of zero air-sea exchange. This shift reflects the fact that $t_{\text {lag }}$ is 
slightly less than 3 months $(1 / 4$ cycle), the lag which would be expected for a gas with infinitely slow air-sea exchange.

Comparing the atmospheric and mixed-layer changes in $\mathrm{O}_{2}$ and $\mathrm{CO}_{2}$, we see that the bulk of the oxygen signal is in the atmosphere while the bulk of the $\mathrm{CO}_{2}$ signal is in the water. Significantly, the amplitude of the change in atmospheric $\mathrm{O}_{2}$, expressed in moles $\mathrm{m}^{-2}$, is more than 10 times greater than that for $\mathrm{CO}_{2}$. The phasing of the atmospheric cycles is such that the drawdown in atmospheric $\mathrm{CO}_{2}$ lags the rise in $\mathrm{O}_{2}$ by 61 days, the difference between $t_{\text {lag }}$ for $\mathrm{CO}_{2}$ and $t_{\text {lag }}$ for $\mathrm{O}_{2}$.

Next, we consider the case where there is no biological activity, and the only forcing is due to seasonal temperature changes. The resulting change's are shown in Figure 2. Again, the changes are partitioned such that $\mathrm{O}_{2}$ variations are predominantly in the atmosphere while the $\mathrm{pCO}_{2}$ variations are primarily in the mixed layer. The amplitude of the change in atmospheric $\mathrm{O}_{2}$ is 4 times greater than the change in atmospheric $\mathrm{CO}_{2}$ on a moles $\mathrm{m}^{-2}$ basis. However, the temperature changes also induce air-sea fluxes of $\mathrm{N}_{2}$ and $\mathrm{Ar}$ which affect the observable $\mathrm{O}_{2} / \mathrm{N}_{2}$ and $\mathrm{O}_{2} / \mathrm{Ar}$ ratios. The relative fluxes of $\mathrm{O}_{2}, \mathrm{~N}_{2}$, and Ar depend primarily on their relative abundances in seawater. Whereas the relative abundance of $\mathrm{N}_{2}: \mathrm{O}_{2}: \mathrm{Ar}$ in air is $78: 21: 1$, their relative concentrations in saturated seawater are about $36: 20: 1$. During warming, the gases are released from seawater roughly in proportion to their dissolved concentrations. The effect of this release, then, is to leave the $\mathrm{O}_{2} / \mathrm{Ar}$ ratio virtually unchanged, while causing the $\mathrm{O}_{2} / \mathrm{N}_{2}$ ratio to rise. The thermal $\mathrm{N}_{2}$ degassing reduces the change in the $\mathrm{O}_{2} / \mathrm{N}_{2}$ ratio to $56 \%$ of what one would expect from the thermal $\mathrm{O}_{2}$ flux alone. Because the solubilities and diffusivities of $\mathrm{Ar}$ and $\mathrm{O}_{2}$ are nearly equal, the Ar degassing nearly perfectly cancels out the effect of $\mathrm{O}_{2}$ degassing on the $\mathrm{O}_{2} / \mathrm{Ar}$ ratio. This suggests that it may be advantageous to measure both $\mathrm{O}_{2} / \mathrm{N}_{2}$ and $\mathrm{O}_{2} / \mathrm{Ar}$ ratios, as the combination will allow thermal and biological fluxes to be

distinguished.

In the final example, we consider the case combining both biological and thermal forcing (Figure 2). For $\mathrm{O}_{2} / \mathrm{N}_{2}$, the biological and thermal fluxes are in phase with each other and combine to yield a change in atmospheric $\mathrm{O}_{2} / \mathrm{N}_{2}$ which is 15\% greater than the biological effect alone. For atmospheric $\mathrm{CO}_{2}$, the biological and thermal effects are diametrically out of phase and virtually cancel each other. Of course, this cancellation is entirely dependent on our choices for the magnitudes and phasing of biological and thermal forcing. On the other hand, recent measurements of the $\mathrm{CO}_{2}$ partial pressure in surface waters [Takahashi et al., 1991] indicate that, between summer and winter, biological and thermal effects on $\mathrm{CO}_{2}$ tend to partially cancel over much of the ocean surface. Incidentally, this suggests that our assumption that 3.5 mole $\mathrm{m}^{-2}$ of carbon are removed seasonally by biological activity is quite reasonable.

To summarize, we have shown, on the basis of a simple model, that (1), as has been long recognized, the inorganic chemistry of $\mathrm{CO}_{2}$ in seawater greatly suppresses seasonal air-sea exchange of $\mathrm{CO}_{2}$ as compared to $\mathrm{O}_{2}$, (2) as a result, marine biological activity produces significant variations in atmospheric $\mathrm{O}_{2}$ without producing comparable changes in atmospheric $\mathrm{CO}_{2}$, and (3) marine temperature changes tend to augment the biological $\mathrm{O}_{2}$ flux and offset the small biological $\mathrm{CO}_{2}$ flux. Although our model vastly oversimplifies the processes occurring in the upper 
ocean, we expect that these conclusions will be generally valid.

\subsection{Water-Column Processes}

The sources and sinks for $\mathrm{O}_{2}$ and $\mathrm{CO}_{2}$ in the mixed layer and deeper

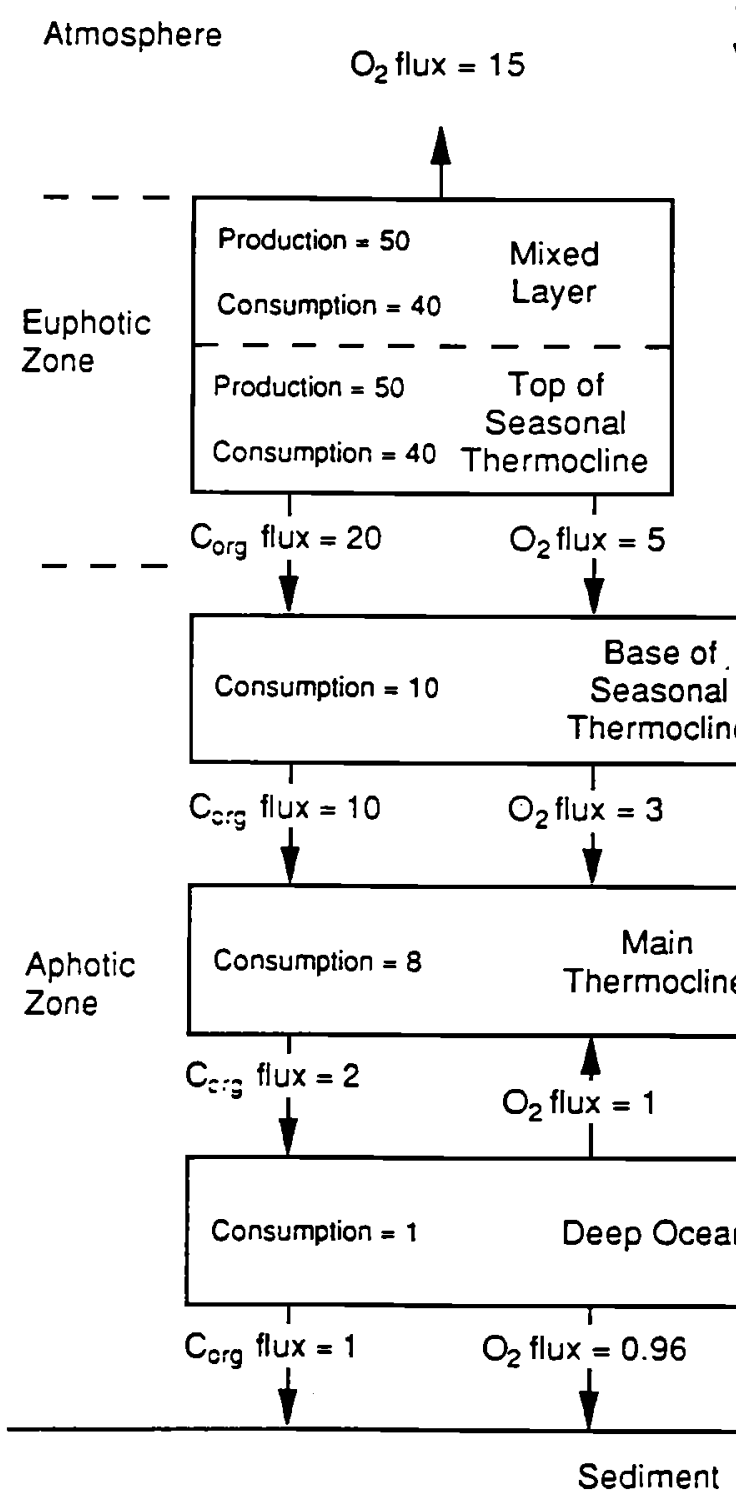

waters are directly coupled to rates of production, transport, and remineralization of organic matter throughout the water column. The coupling is illustrated in Figure 3 which examines the fate of 100 units of organic carbon produced in the euphotic zone. We will adopt

\section{Wintertime Thermocline Deep Water} Ventilation, Ventilation, Ventilation $\mathrm{O}_{2}$ flux $=8 \quad \mathrm{O}_{2}$ flux $=4 \quad \mathrm{O}_{2}$ flux $=2.96$
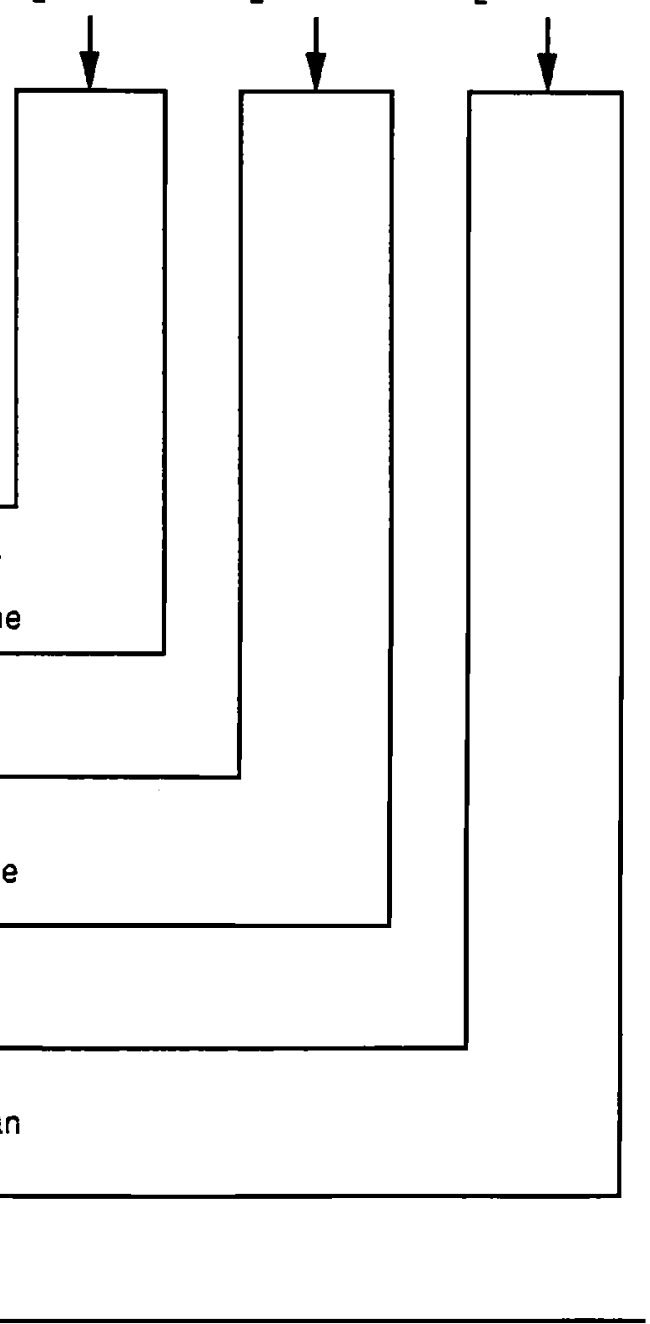

Fig. 3. Schematic representation of oceanic oxygen cycle and organic carbon cycle. There is a net longterm burial of 0.04 units of organic carbon which results in a net flux of 0.04 units of oxygen into the atmosphere. This flux is presumably balanced by weathering of sedimentary rocks. 
units such that 100 arbitrary units of organic carbon produced correspond to 100 units of $\mathrm{O}_{2}$ produced. Values adopted for the fluxes are suitable for illustration but in practice these values vary greatly both in space and time. In the diagram there are six reservoirs: the atmosphere, the euphotic zone, the base of the seasonal thermocline, the main thermocline, the deep ocean, and the sediments. As formulated here, the mixed layer and seasonal thermocline are distinct in summer; in the wintertime they combine to form one wellmixed box. The top of the summertime seasonal thermocline is part of the euphotic zone and is a site of net autotrophy. The base of the summertime seasonal thermocline is part of the aphotic zone, and a site of net heterotrophy. The main thermocline outcrops to the sea surface along isopycnals during deep winter convection at temperate and subpolar latitudes. The deep ocean outcrops along isopycnals during winter at polar latitudes.

There are four general possibilities for the fate of organic matter produced in the euphotic zone. First, and most likely, the organic matter may be rapidly remineralized within the euphotic zone. Remineralization of this organic matter consumes as much $\mathrm{O}_{2}$ as was produced during photosynthesis with the result that there is no change in the water column $\mathrm{O}_{2}$ concentration and no imprint on the atmospheric $\mathrm{O}_{2}$ distribution. In our example, 50 units of $\mathrm{O}_{2}$ and organic carbon are produced in the mixed layer, and 40 are immediately consumed by respiration. Likewise, 50 units are produced and 40 are consumed in the top of the seasonal thermocline.

Second, organic matter produced in the euphotic zone may be oxidized in the lower region of the seasonal (summertime) thermocline.
This process accounts, for example, for the $\mathrm{O}_{2}$ undersaturation of water at 100-150 $\mathrm{m}$ depth off Bermuda [Jenkins and Goldman, 1985]. The production of this organic matter, which occurs predominantly in spring and summer, is associated with a net production of $\mathrm{O}_{2}$ in the euphotic zone. Some of this $\mathrm{O}_{2}$ escapes into the atmosphere, some is removed from the euphotic zone by mixing into deeper waters, while some simply accumulates in the euphotic zone, accounting for the well-known subsurface $\mathrm{O}_{2}$ maximum [e.g., Shulenberger and Reid, 1981]. Eventualiy, the accumulated $\mathrm{O}_{2}$ is also lost, either by escaping into the atmosphere or by downward mixing into deeper water. In fall and winter, after the breakdown of stratification, $\mathrm{O}_{2}$ undersaturated water from the base of seasonal thermocline mixes back up to the surface. Upon exposure to the atmosphere, this water reabsorbs as much $\mathrm{O}_{2}$ as was exported to the atmosphere during the previous summer. The production of organic matter which is destined to be remineralized at the base of the seasonal thermocline is thus associated with a seasonal cycle whereby $\mathrm{O}_{2}$ is released to the atmosphere in the spring and summer and $\mathrm{O}_{2}$ is removed from the atmosphere in the fall and winter. At any point on the sea surface, input and output of this $\mathrm{O}_{2}$ component are equal when integrated over the year. The imprint of these fluxes on the atmosphere consists of a seasonal variation with a minimum in the late winter. In our example, 10 units of organic matter are oxidized in the base of the seasonal thermocline, consuming 10 units of oxygen. An additional three units of oxygen are removed from the base of the seasonal thermocline by mixing with deeper waters. Of the total of 13 units removed, eight are replenished during the winter outcrop while 
five are restored by mixing from the top of the seasonal

thermocline.

Third, some organic matter may sink to be remineralized in the main thermocline. The production of this organic matter within the euphotic zone results in a net source of $\mathrm{O}_{2}$ which, again, is partly lost to the atmosphere and partly lost by downward mixing. Some of the $\mathrm{O}_{2}$ consumed within the main thermocline will be imported from the atmosphere at a more poleward latitude where the thermocline water outcrops during the wintertime period of deep convection [Kawase and Sarmiento, 1985; Glover and Brewer, 1988]. The rest of the $\mathrm{O}_{2}$ consumed is restored by mixing from above and below. Production of organic matter and remineralization in the main thermocline is thus accompanied by release of $\mathrm{O}_{2}$ to the atmosphere in the subtropical and lower temperate latitudes and uptake of atmospheric $\mathrm{O}_{2}$ in wintertime in the more poleward temperate regions. These fluxes imprint on atmospheric $\mathrm{O}_{2} / \mathrm{N}_{2}$ a seasonal variation with a minimum in the late winter and a north-south gradient with higher annual-mean concentrations at lower latitudes. In our example, eight units of organic matter are oxidized in the main thermocline removing eight units of oxygen. Four of these eight units are replaced during the winter outcrop, three are replaced by mixing from above and one unit is restored by mixing from below.

Finally, throughout the tropics, subtropics, and temperate regions, some organic matter will sink into the deep oceans or into the sediments and be oxidized there. The air-sea fluxes of $\mathrm{O}_{2}$ associated with these organic matter fluxes are qualitatively similar to those caused by organic matter recycled in the main thermocline. In this case, however, the outcropping regions are even further poleward and the outcropping may be episodic. In the example, one unit of organic matter is oxidized in deep water and 0.96 units are oxidized in the sediments. Together this consumes 1.96 units of $\mathrm{O}_{2}$ from deep water. Additionally, one unit of $\mathrm{O}_{2}$ is removed from deep water by mixing with the overlying thermocline. The total of 2.96 units removed are all replaced during the winter outcrop.

In summary, the production, transport, and consumption of organic carbon in the ocean is accompanied by fluxes of $\mathrm{O}_{2}$ across the air-sea interface which, in turn, cause variability in the $\mathrm{O}_{2} / \mathrm{N}_{2}$ ratio of air. There is a seasonal component to this variability which results from export to the atmosphere of $\mathrm{O}_{2}$ associated with net euphotic zone production in the spring and summer, and import from the atmosphere associated with wintertime deep convection. There is also a north-south component to the variability in the $\mathrm{O}_{2} / \mathrm{N}_{2}$ ratio associated with the poleward location of sites where the thermocline and deep ocean are ventilated.

\subsection{Nutrient Controls}

The $\mathrm{O}_{2}$ fluxes through the ocean, and hence the air-sea $\mathrm{O}_{2}$ fluxes, are driven by the flux of waters into the mixed layer which bear nutrients needed to support biological activity. Waters which bear nutrients are generally undersaturated in oxygen and therefore present to the atmosphere an immediate oxygen demand as well as a potential oxygen source associated with the transport of nutrients. Whether a given oceanic region is a source or sink of $\mathrm{O}_{2}$ to the atmosphere depends critically on the interplay between fluxes of oxygen undersaturated water (or apparent oxygen utilization (AOU), defined as $\left[\mathrm{O}_{2}\right]_{\text {g }}-\left[\mathrm{O}_{2}\right]$ ) and the flux 
of nutrients into the mixed layer. This interplay can be quantified in terms of the pre-formed nutrient concentration of the water entering the mixed layer. Preformed nutrients are the nutrients which were present in the water when it was last exposed to the surface. operationally, preformed $\mathrm{PO}_{4}^{=}$can be defined by the equation (Redfield et al., 1963):

$$
\left[\mathrm{PO}_{4}^{\mathrm{E}}\right]_{\mathrm{pre}}=\left[\mathrm{PO}_{4}^{\mathrm{z}}\right]-R_{\mathrm{PO}_{4}^{\mathrm{E}: \mathrm{O}_{2}}} \cdot \mathrm{AOU}
$$

where $R_{\mathrm{PO}_{4}: \mathrm{O}_{2}}$ equals the number of moles of $\mathrm{PO}_{4}=$ produced per mole of $\mathrm{O}_{2}$ consumed during remineralization. We consider two extreme cases. In the first, no $\mathrm{PO}_{4}^{=}$entering the mixed layer is consumed by biological activity. The net release of $\mathrm{O}_{2}$ to the atmosphere per unit volume of water entering the mixed layer is then equal to -AOU. This case approximates the case of wintertime convection. In the second case, all $\mathrm{PO}_{4}^{\bar{F}}$ is utilized in the production of organic matter. In this case, the net release of $\mathrm{O}_{2}$ to the atmosphere is equal to the production less the AOU demand which is given by $\left[\mathrm{PO}_{4}^{=}\right] / R_{\mathrm{PO}}: \mathrm{O}_{2}-\mathrm{AOU}=$ $\left[\mathrm{PO}_{4}^{*}\right]_{\text {pref }} / R_{\mathrm{PO}_{4}^{*}: \mathrm{O}_{2}}$. There is still a net flux of $\mathrm{O}_{2}$ to the air, but it is smaller by an amount equal to the AOU. This case approximates the situation for oligotrophic waters in the summertime. In either case the net release of $\mathrm{O}_{2}$ to the atmosphere per unit volume of seawater entering the mixed layer is stoichiometrically linked to the net decrease in the preformed nutrient content of the water during its residence in the mixed layer. In fact, the proportionality between the net airsea $\mathrm{O}_{2}$ flux and the change in preformed nutrients can easily be shown to hold more generally for intermediate cases as well.

To a close approximation preformed nutrients, as defined, for example, by Equation (18), are a conservative tracer of seawater which can only be modified at the surface. Our analysis shows that the changes in preformed nutrients at the surface are directly linked to air-sea oxygen fluxes. Changes in the inventory of preformed nutrients in the ocean thus are linked via the Redfield ratio to changes in atmospheric $\mathrm{O}_{2}$. The regions of the ocean surface that have a high surface nutrient concentration, for example, high latitudes in winter, are generally a source of preformed nutrients to deeper waters. Such regions therefore tend to be a sink for atmospheric $\mathrm{O}_{2}$. Conversely, regions with low surface nutrient concentration, for example, oligotrophic gyres in summer, tend to be a net sink for preformed nutrients mixing up from deeper waters. Such regions tend to be a net source for atmospheric $\mathrm{O}_{2}$. These points are illustrated in Figure 4 .

\section{PREDICTED ATMOSPHERIC $\mathrm{O}_{2}$}

\section{VARIATIONS}

\subsection{Modeling strategy}

We now turn to the problem of estimating the magnitude of the variations in the atmospheric $\mathrm{O}_{2} / \mathrm{N}_{2}$ and $\mathrm{O}_{2} / \mathrm{Ar}$ ratios which result from exchanges with the ocean, exchanges with terrestrial biosphere, and the burning of fossil fuel. For the present we will ignore the constraints imposed by the existing measurements of atmospheric $\mathrm{O}_{2}$ [Keeling and shertz, 1992] by basing the source estimates on a priori specifications of the source fields. Comparison of such predictions with observations is a task for the future.

our approach is to construct estimates of the fluxes of $\mathrm{O}_{2}, \mathrm{~N}_{2}$, and $A r$ as a function of latitude 


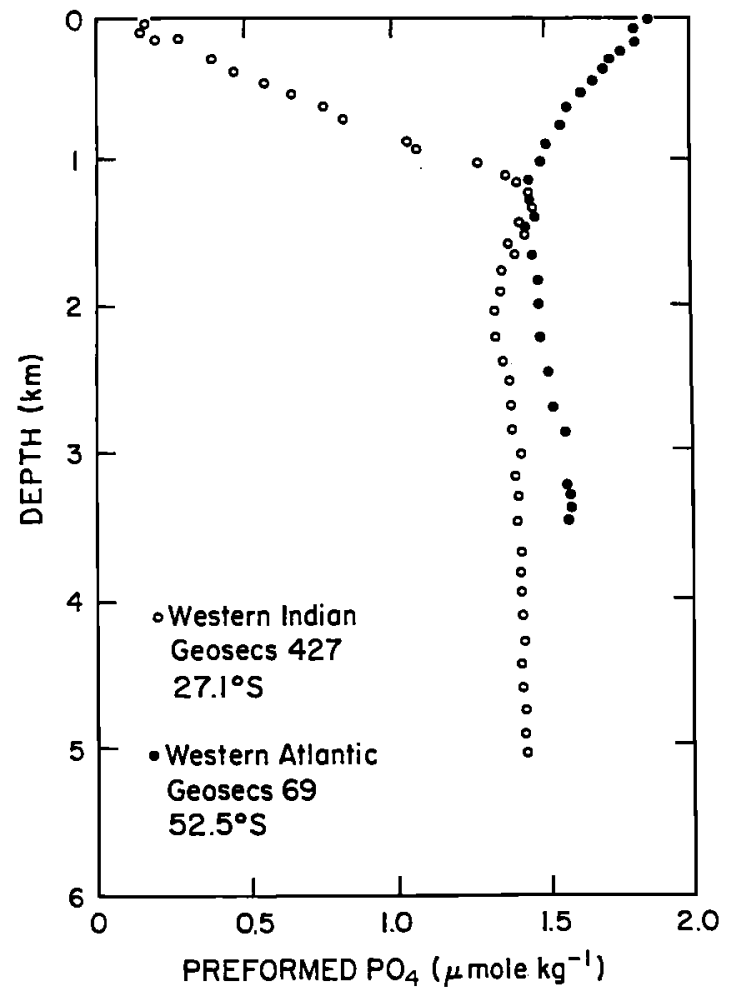

Fig. 4. Vertical profiles in preformed phosphate, at $52.5^{\circ} \mathrm{s}$ in the western Atlantic ocean and at $27.1^{\circ} \mathrm{S}$ in the western Indian Ocean, from Broecker et al. [1985]. At $52.5^{\circ} \mathrm{S}$, preformed phosphate decreases with depth to $1000 \mathrm{~km}$ implying a net downward flux of preformed phosphate away from the surface and thus a net sink for atmospheric $\mathrm{O}_{2}$ at the surface. At $27.1^{\circ} \mathrm{S}$, preformed phosphate increases with depth to $1 \mathrm{~km}$ implying a net upward flux of preformed phosphate toward the surface and thus a net source for atmospheric $\mathrm{O}_{2}$ at the surface.

and season, and to compute the variations in the atmospheric concentration using a twodimensional (latitude and height) atmospheric transport model. The two-dimensional model is based on a set of advection and diffusion coefficients derived from the GFDL general circulation model [Plumb and Mahlman, 1987]. The twodimensional horizontal transport has been validated by calculating the north-south concentration gradients of $\mathrm{CFC}-12$ and ${ }^{85} \mathrm{Kr}$. Vertical transport in the northern hemisphere has been calibrated using the observed attenuation and phase lag of the seasonal cycle of $\mathrm{CO}_{2}$ as a function of altitude. The model was originally developed to calculate, as a function of time, the latitudinal distribution for $\mathrm{CO}_{2}$ sources and sinks consistent with several years of $\mathrm{CO}_{2}$ surface observations; it has been described by Tans et al. [1989]. To generate the oxygen distributions, the sources are defined as outlined below and the model is run for 3 years each time, in order to reach a steady state. Running the model for more than 3 years produces essentially the same results.

The transport model is linear with respect to atmospheric concentration, and thus we can represent the atmospheric concentration field as a linear combination of fields resulting from separate source components. We divide the source fields into two general categories: (1) seasonally varying sources which, by definition, are constrained to be locally balanced, i.e., the annual average of the flux at each surface grid location is zero, and (2) stationary sources which are constant with time at each grid location. For example, ocean ventilation fluxes of $\mathrm{O}_{2}$ which result in net loss of $\mathrm{O}_{2}$ from the atmosphere at high latitudes, but which operate only during winter, will contribute both to the seasonally varying source field and to the stationary source field. our calculations neglect the possibility of interannual variations in the $\mathrm{O}_{2}$ sources and sinks.

The atmospheric concentration field can be decomposed into an 
annual-mean field and a seasonally varying field for which the annualmean concentration is zero at each location. Thus we may consider the concentration fields as comprised of four general components: (1) seasonal fields which result from the seasonal sources, (2) annualmean fields which result from the stationary sources, (3) seasonal fields which result from the stationary sources, and (4) annualmean fields which result from the seasonal sources. The latter two components result from seasonal variations in the transport fields. All four fields are calculated by our model, but we do not discuss the latter two components because their contribution to the total fields is small and because we are not confident that they are reliably predicted by the transport model.

The transport model is run with the following source fields: (1) a stationary sink of oxygen due to fossil fuel burning, (2) a stationary source or sink due to long-term exchanges with the land biosphere, (3) a stationary source or sink from the ocean surface which is related to the north-south transport of heat within the ocean, (4) a stationary source or sink from the ocean surface due to marine biological activity, (5) a seasonal source or sink of $\mathrm{O}_{2}$ from the terrestrial biosphere, (6) a seasonal source or sink of $\mathrm{O}_{2}, \mathrm{~N}_{2}$, and $\mathrm{Ar}$ due to changes in ocean temperature, and (7) a seasonal source or sink from the ocean surface due to the marine biosphere.

\subsection{Stationary sources}

We calculate the sink of oxygen due to fossil fuel burning by scaling the fossil fuel $\mathrm{CO}_{2}$ source [Rotty, 1986] for the year 1980 $\left(5.2 \times 10^{15} \mathrm{~g} \mathrm{C} / \mathrm{yr}\right)$, according to the average stoichiometry of combustion of $1.42: 1$ for $\mathrm{O}_{2}: \mathrm{CO}_{2}$. This stoichiometry is obtained by using stoichiometry for the individual fuel types (1.95:1 for gaseous fuels, 1.44:1 for liquid fuels, 1.17: 1 for solid fuels, and 1.98:1 for natural gas flaring [Keeling, 1988], taking account of relative production of different fuel types for the year 1980 [Rotty, 1983]. The seasonality of combustion is minor [Rotty, 1987]. The latitudinal distribution of the oxygen sink from burning fossil fuel is shown in Figure 5 .

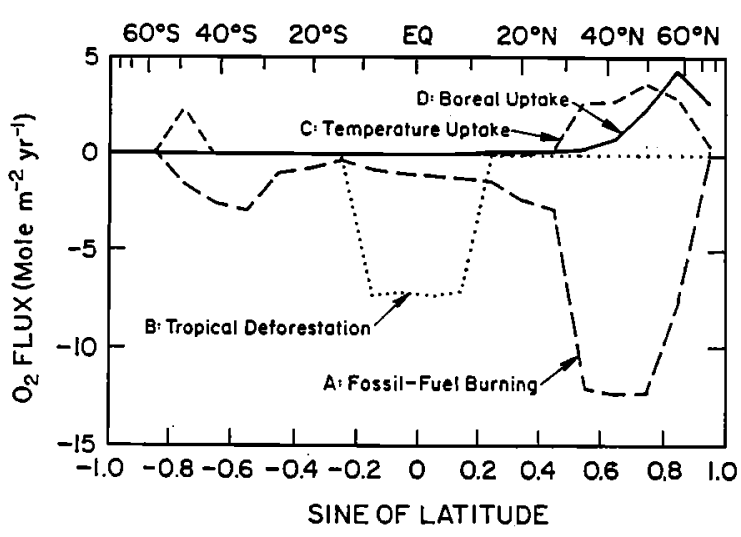

Fig. 5. Showing zonally averaged annual-mean oxygen fluxes from terrestrial sources and sinks. Fluxes from tropical deforestation, temperate uptake, and boreal uptake are scaled according to a total $\mathrm{CO}_{2}$

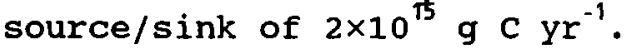
Fluxes are expressed per unit land area.

Tropical deforestation is estimated to contribute to a net source of $\mathrm{CO}_{2}$ of around $1 \times 10^{15}$ g C $\mathrm{yr}^{-1}$ [Detwiler and Hall, 1988], while uptake from temperate or boreal systems may contribute to a sink of comparable magnitude. However, there is currently considerable uncertainty surrounding the magnitude and distribution of changes in carbon storage on land. Such changes may be caused by a variety of processes including land 
use changes, climatic change, fertilization from increased $\mathrm{CO}_{2}$, or other agents. We consider three scenarios: (1) tropical ecosystems are a source of $2 \times 10^{15} \mathrm{~g} \mathrm{C} \mathrm{yr}^{-1}$, (2) temperate ecosystems are a sink of $2 \times 10^{15} \mathrm{~g} \mathrm{C} \mathrm{Yr}^{-1}$, (3) boreal systems are a sink of $2 \times 10^{15} \mathrm{~g} \mathrm{C} \mathrm{yr}^{-1}$. The first two scenarios correspond roughly to scenarios 3 and 5 in the work by Tans et al. [1990]. The calculations assume a stoichiometry of 1.05:1 for $\mathrm{O}_{2}: \mathrm{C}$. The latitudinal distribution of the $\mathrm{O}_{2}$ fluxes from each of these scenarios is shown in Figure 5 .

The transport of heat by the oceans is accompanied by a transport of soluble gases, for example, $\mathrm{O}_{2}, \mathrm{~N}_{2}$, and $\mathrm{Ar}$. Thus when cold water from high latitudes is transported to low latitudes and warmed, gases are released to the atmosphere. Likewise, when warm water from low latitudes is transported to high latitudes and cooled, gases are removed from the atmosphere. We compute the corresponding airsea fluxes according to the relation

$$
F=-\frac{d C_{e g}}{d T} \frac{\dot{Q}}{C_{p}}
$$

where $F$ is the net efflux in moles $\mathrm{m}^{-2} \mathrm{~s}^{-1}, \mathrm{dC}_{\mathrm{eq}} / \mathrm{dT}$ is the temperature derivative of the solubility in mole $\mathrm{m}^{-3} \mathrm{~K}^{-1}, \dot{Q}$ is the net air-to-sea heat flux (sum of sensible, latent, long, and shortwave fluxes) in $J \mathrm{~m}^{-2}$ $\mathrm{s}^{-1}, C_{p}$ is the heat capacity of seawater in $\mathrm{J} \mathrm{m}^{-3} \mathrm{~K}^{-1}$, and where we linearized the temperaturesolubility relation. The approach will tend to overestimate the gas fluxes because Equation (19) assumes that surface waters fully equilibrate. For consistency, we use the annual-mean heat flux data from the ice-free regions as derived from the three-dimensional ocean model [Toggweiler et al., 1989], which served as the basis for the biological model of Najjar et al. [1992]. We normalize the calculated fluxes so that the global flux is zero by adding a constant flux uniformly over the sea surface. The latitudinal distribution of the annual-mean $\mathrm{O}_{2}$ source from ocean temperature is shown in Figure 6 (curve $A$ ). $O_{2}$ is released at the Equator, where heating of upwelling waters causes thermal effusion, and $\mathrm{O}_{2}$ is taken up at high latitudes where the opposite occurs. The effect of this source on the atmospheric $\mathrm{O}_{2} / \mathrm{N}_{2}$ ratio is reduced by a factor of 0.56 by the compensating thermal flux of $\mathrm{N}_{2}$ (see the discussion in section 2).

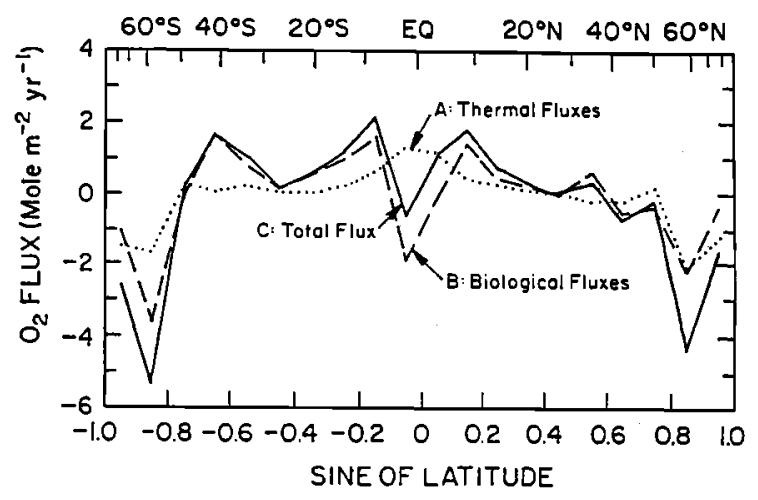

Fig. 6. Showing zonally averaged annual-mean oxygen fluxes from the ocean. Fluxes are separated into a thermal component related to local net heat flow, and a biological component related to local imbalances between new production and ventilation. The total flux is the sum of the thermal and biological components. Fluxes are expressed per unit ocean area.

The three-dimensional model of Najjar et al. [1992] provides estimates of net annual-mean airsea oxygen fluxes over a twodimensional grid of the ocean surface. This flux field includes the biological component from new production and aphotic respiration as well as the abiological 
component related to the heat fluxes. In order to extract the biological component, we subtract the fluxes driven by heat flow (derived above) from the net fluxes calculated by the model. We normalize the calculated biological fluxes so that the global flux is zero by adding a constant flux uniformly over the sea surface. In terms of the physical premises of the three-dimensional model, this constant flux represents the small fraction of water column respiration associated with reduction of $\mathrm{NO}_{3}{ }^{-}$rather than $\mathrm{O}_{2}$. This annual-mean $\mathrm{O}_{2}$ source field, averaged over latitude bands, is shown in Figure 6 (curve B).

\subsection{Predicted Annual-Mean Gradients}

Figure 7 shows the north-south distribution of atmospheric $\mathrm{O}_{2} / \mathrm{N}_{2}$ at the surface resulting from each of the stationary sources considered in isolation. In this plot, hypothetical sea level air at $90^{\circ} \mathrm{s}$

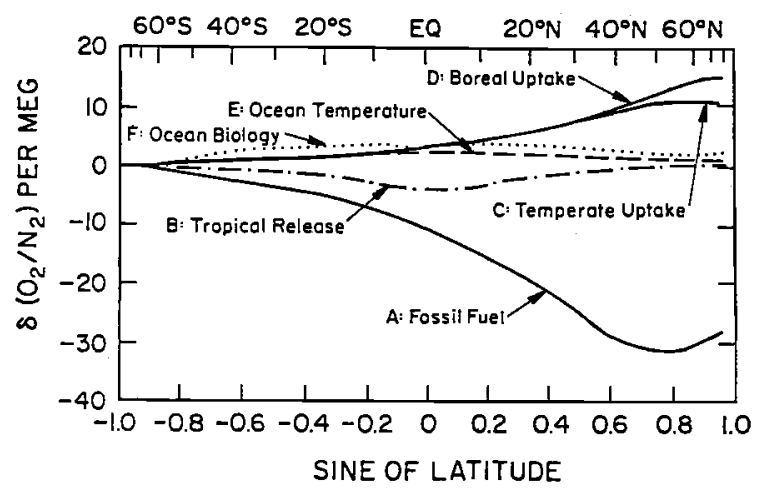

Fig. 7. Gradients in annual-mean $\mathrm{O}_{2} / \mathrm{N}_{2}$ produced as a result of isolated processes. Fossil burning in 1980; release of $2 \times 10^{15}{\mathrm{~g} \mathrm{C} \mathrm{yr}^{-1}}^{-1}$ from terrestrial tropical ecosystems; $C$ and D: uptake of $2 \times 10^{t 5} \mathrm{~g} \mathrm{yr}^{-1}$ from temperate and boreal terrestrial ecosystems, respectively ocean meridional heat flux; ocean biology. serves as a reference. The burning of fossil fuel occurs predominantly in the northern hemisphere, leading to a reduction of $\mathrm{O}_{2} / \mathrm{N}_{2}$ of approximately 30 per meg in the middle latitudes of the northern hemisphere relative to the southern hemisphere. Uptake of $2 \times 10^{15} \mathrm{~g}$ C $\mathrm{yr}^{-\uparrow}$ from temperate ecosystems or from boreal ecosystems produces a gradient opposite to that of fossil fuel burning, with an excess of approximately 10 per meg at mid northern latitudes. Uptake by boreal ecosystems is virtually indistinguishable from uptake by temperate ecosystems except at high northern latitudes. Tropical release of $2 \times 10^{15} \mathrm{~g} \mathrm{C} \mathrm{yr}^{-t}$ produces a deficiency of only 4 per meg in the tropics relative to the poles. The relative insensitivity of the surface concentration in the tropics to the local sources is the result of the efficient vertical mixing. The air-sea fluxes of oxygen due to biological processes and thermal processes produce a small excess in $\mathrm{O}_{2} / \mathrm{N}_{2}$ in the tropics relative to the high latitudes.

Figure 8 illustrates the northsouth gradient produced when the sources are combined under different scenarios. The first scenario considers only sources from fossil fuel and the oceans.

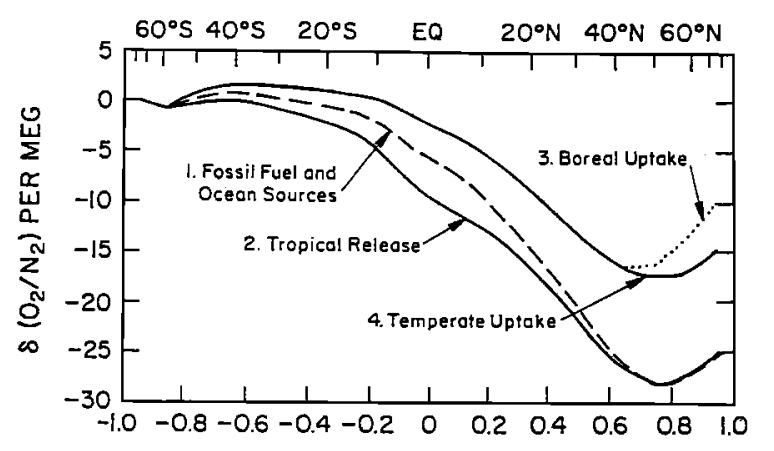

Fig. 8. Gradient in annual-mean $\mathrm{O}_{2} / \mathrm{N}_{2}$ produced under four scenarios for the annual-mean source fields (see text). 
The ocean fluxes have only a minor influence on the distribution. The second scenario adds $2 \times 10^{15}{\mathrm{~g} \mathrm{C} \mathrm{yr}^{-1}}^{-1}$ of tropical deforestation, and this only slightly reduces concentrations in the tropics. The third and fourth scenarios add $2 \times 10^{15} \mathrm{~g}$ $\mathrm{yr}^{-1}$ of temperate uptake and $2 \times 10^{15} \mathrm{~g} \mathrm{C} \mathrm{Yr}^{-1}$ of boreal uptake to the fluxes from fossil fuel burning and oceanic fluxes. In both scenarios the difference in $\mathrm{O}_{2} / \mathrm{N}_{2}$ between the middle latitudes of the northern and southern hemispheres is reduced by 10 per meg relative to that predicted in the first two scenarios. Thus oxygen measurements with a precision of 5 per meg should be able to constrain the net uptake of boreal and temperate ecosystems to the level of $10^{15} \mathrm{~g} \mathrm{C}$ $\mathrm{yr}^{-1}$.

\subsection{Seasonal Sources}

The natural seasonal cycle of photosynthesis and decay of land plants results in a net uptake of $\mathrm{CO}_{2}$ by temperate and boreal ecosystems during the late spring and summer that is returned to the atmosphere throughout the remainder of the year, particularly in the fall and early spring. We adopt a schematic representation of the seasonal fluxes which is similar to that inferred from $\mathrm{CO}_{2}$ measurements by Tans et al. [1989]. Others have examined the problem previously, using a variety of approaches [Bolin and Keeling, 1963; Pearman and Hyson, 1980; Fung et al., 1983]. We calculate $\mathrm{O}_{2}$ fluxes from the $\mathrm{CO}_{2}$ fluxes assuming a stoichiometric ratio of $1.05: 1 \quad\left(\mathrm{O}_{2}: \mathrm{CO}_{2}\right)$ for the photosynthetic production and respiratory destruction of terrestrial biospheric material on a seasonal time scale. Note that Keeling [1988] estimated an average ratio of $1.05: 1$ for wood and a ratio of $1.07: 1$ for soil organic matter. Bloom et al. [1989], in experiments examining individual barley shoots, found ratios of 1.0:1 except under conditions of high nitrate assimilation which caused ratios to vary by as much as 25\%. The seasonal $\mathrm{O}_{2}$ source fields from the terrestrial biosphere, averaged over several latitude bands, are shown in Figure 9. The source fields neglect the small contribution from terrestrial ecosystems in the southern hemisphere.

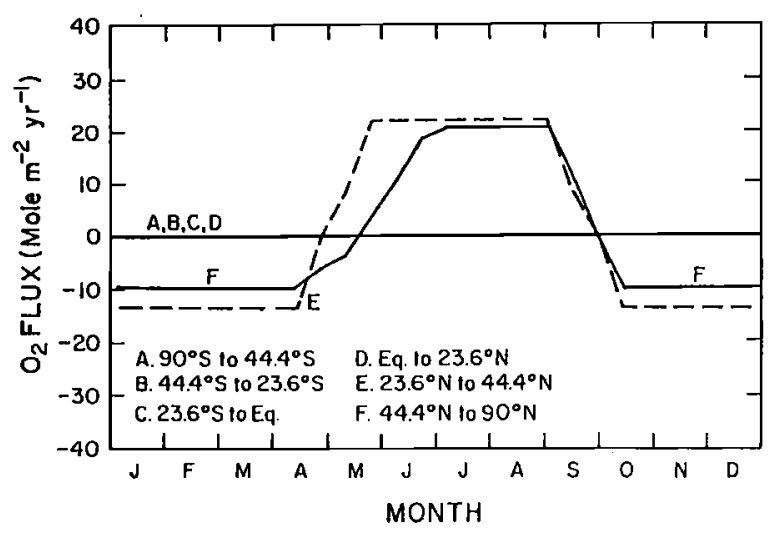

Fig. 9. Seasonal sources and sinks of $\mathrm{O}_{2}$ from exchanges with terrestrial ecosystems, shown as averages over six latitude bands. Fluxes are expressed per unit land area.

We estimate the thermally driven fluxes of $\mathrm{O}_{2}, \mathrm{~N}_{2}$, and $\mathrm{Ar}$ across the air-sea interface by making the approximation that air-sea gas exchange is sufficiently rapid that dissolved $\mathrm{O}_{2}, \mathrm{~N}_{2}$, and $\mathrm{Ar}$ remain in equilibrium with the atmosphere over the seasonal cycle. The results of the mixed-layer model described in section 2 indicate that this approximation should yield reasonable estimates of the gas fluxes. With this approximation the local gas flux is proportional to the local air-sea heat flux. We further assume that the local heat flux can be approximated by the local change in heat storage. Although this approxi- 
mation neglects lateral transport, it should provide reasonable estimates of the seasonal component of the heat fluxes when integrated over large scales.

With these assumptions we can estimate the gas exchange fluxes at any location using Equation (19) where $\dot{Q}$ now refers to the seasonal rate of change of heat storage at that location. If we had used a finite air-sea exchange rate, we would estimate fluxes that are smaller than those calculated from Equation (19). Thus the approach yields an upper limit to the airsea fluxes.

We calculate the seasonal heat storage by zonally averaging maps from Samuels and cox [1987]. We assume that the temperature derivative of the solubility is constant at each location, using a value appropriate for the average sea surface temperature. The source fields for $\mathrm{O}_{2}$, averaged over six latitude bands, are shown in Figure 10. As expected, the sources in the tropics are smaller than those at higher latitudes. The seasonal heat storage in the

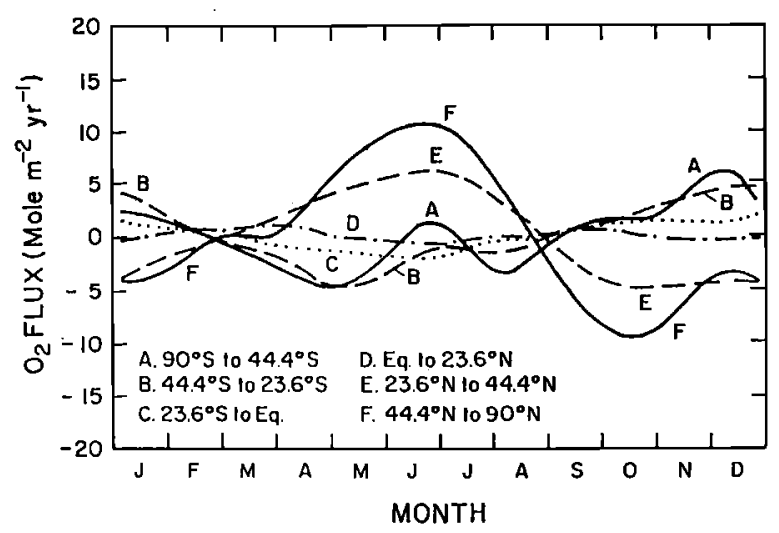

Fig. 10. Seasonal sources and sinks of $\mathrm{O}_{2}$ from thermally driven air-sea exchange, shown as averages of six latitude bands. Fluxes are computed using solubility data of Weiss [1970]. Fluxes are expressed per unit ocean area. southern hemisphere is smaller, when expressed per unit area of sea surface, than that of the northern hemisphere, and thus the southern hemispheric oxygen fluxes are also smaller.

To calculate changes in the observable $\mathrm{O}_{2} / \mathrm{N}_{2}$ or $\mathrm{O}_{2} / \mathrm{Ar}$ ratios, we must also account for the thermally driven fluxes of $\mathrm{N}_{2}$ and Ar. As discussed in section 2 , the flux of $\mathrm{N}_{2}$ partially compensates for the flux of $\mathrm{O}_{2}$ such that the changes in $\mathrm{O}_{2} / \mathrm{N}_{2}$ are reduced to $56 \%$ of what one calculates from the $\mathrm{O}_{2}$ flux alone. The thermal Ar flux almost completely cancels out the effect of the $\mathrm{O}_{2}$ flux on the $\mathrm{O}_{2} /$ Ar ratio.

We adopt two highly simplified but independent approaches to estimating air-sea oxygen fluxes driven by marine biological activity. In the first approach, we estimate the zonally and annually averaged $\mathrm{O}_{2}$ source associated with new production, and $\mathrm{O}_{2}$ loss associated with ventilation of waters below the euphotic zone. These estimates are based partly on the three-dimensional ocean model of Najjar et al. [1992] and partly on empirical data for new production in the northern hemisphere, as described in Appendix A. Between $10^{\circ} \mathrm{S}$ and $10^{\circ} \mathrm{N}$ we assume that new production and ventilation fluxes are constant throughout the year. over the remainder of the globe we compute the seasonally varying new production and ventilation fluxes by multiplying the annual-mean values for each latitude by the normalized seasonal functions shown in Figure 11. These functions assume that the new production rate is 3 times greater during the spring and summer than during fall and winter, and the ventilation takes place only in the fall and winter. We calculate latitudinally dependent and seasonally varying $O_{2}$ fluxes to the atmosphere as the difference between the $\mathrm{O}_{2}$ new production and the ventilation flux. Note that by invoking a 

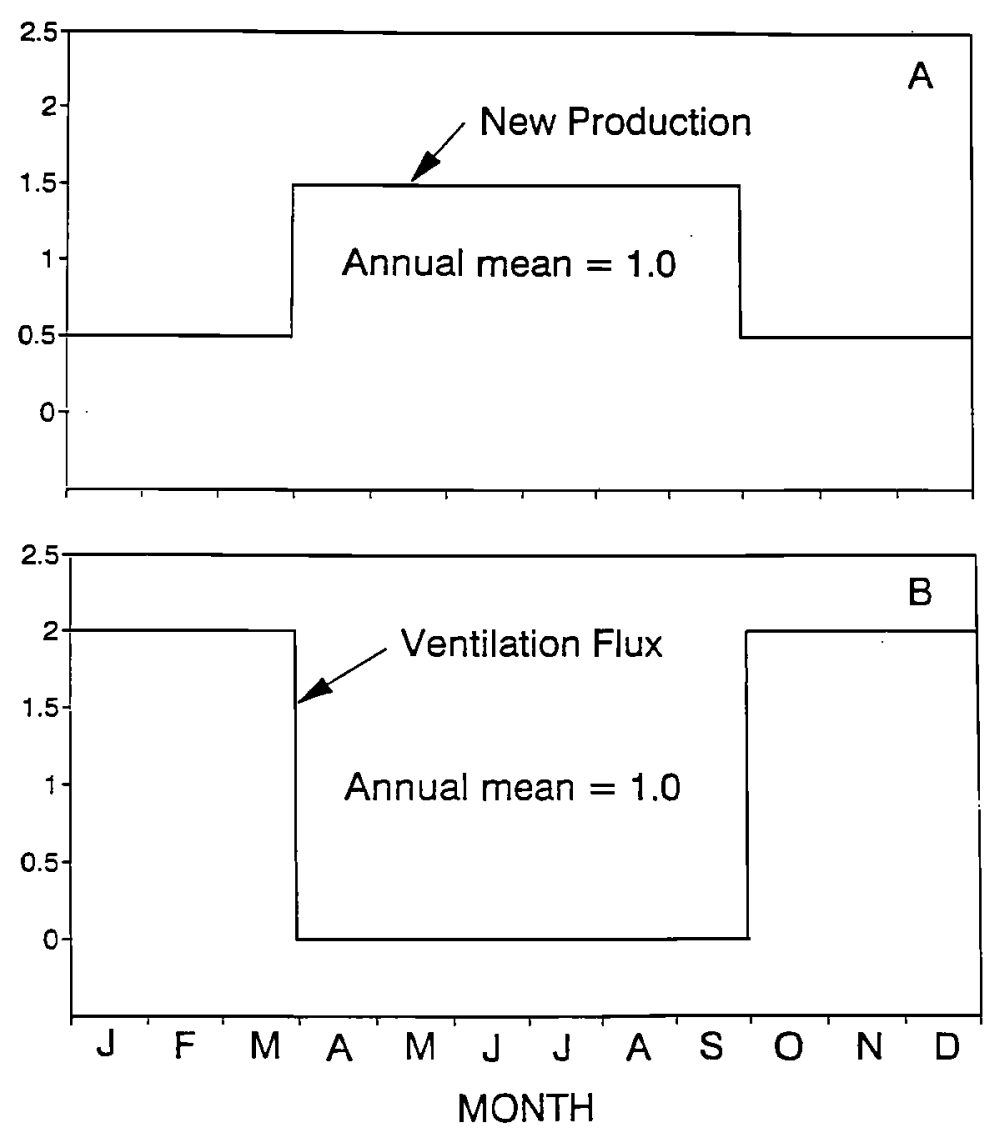

Fig. 11. Normalized functions representing seasonal variations in new production and ventilation used for model calculations in the

balance between new production, ventilation, and air-sea $\mathrm{O}_{2}$ exchange, our treatment neglects any possible seasonal accumulation of $\mathrm{O}_{2}$ within the euphotic zone. Finally, we force the fluxes to be locally balanced by subtracting off the annual-mean air-sea fluxes at each latitude band. The locally balanced flux fields, averaged over six latitude bands, are shown in Figure 12 .

In the second approach to estimating the biologically driven air-sea fluxes of $\mathrm{O}_{2}$ we use the difference between the $\mathrm{pCO}_{2}$ of surface water in summertime and wintertime to estimate the seasonal difference in the DIC inventory and hence the seasonal net production of organic carbon and $\mathrm{O}_{2}$. In making northern hemisphere. In the southern hemisphere, the functions are shifted by 6 months.

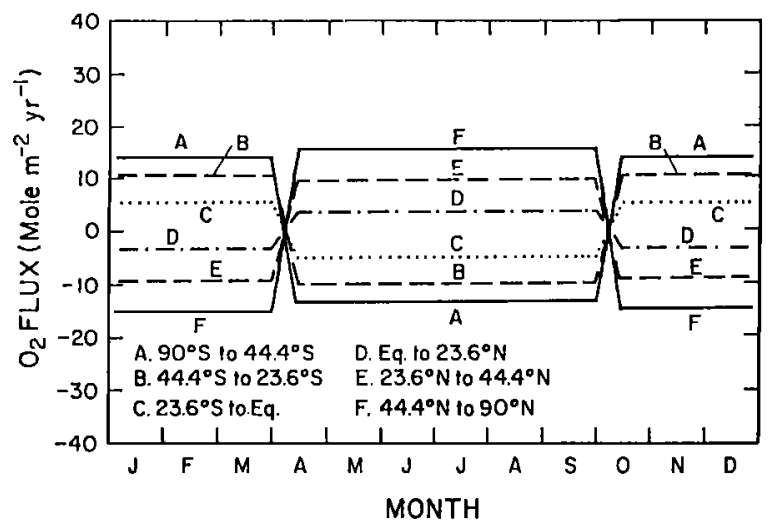

Fig. 12. Seasonal sources and sinks of $\mathrm{O}_{2}$ due to air-sea exchange driven by marine biosphere, shown as averages over six latitude bands. Sources are based on the "first" ocean model (see text). Fluxes are expressed per unit ocean area. 
this estimate, we take advantage of recent evidence that $\mathrm{pCO}_{2}$ of surface waters tends to correlate with the surface water temperature [Takahashi et al., 1991]. The seasonal change in $\mathrm{pCO}_{2}$ is controlled thermodynamically by changes in water temperature, DIC, and titration alkalinity (ALK):

$$
\begin{aligned}
& \delta \ln P_{C O_{2}}=\left(\frac{\partial \ln P_{\mathrm{CO}_{2}}}{\partial T}\right)_{D I C, A L K} \delta T+ \\
& \left(\frac{\partial \ln P_{\mathrm{CO}_{2}}}{\partial D I C}\right)_{T, A L K} \delta D I C+\left(\frac{\partial \ln P_{C O_{2}}}{\partial A L K}\right)_{T, D I C} \delta A L K
\end{aligned}
$$

where $T$ is the temperature, $P_{\mathrm{CO}_{2}}$ is the partial pressure of $\mathrm{CO}_{2}$ in the water, $D I C$ is total dissolved inorganic carbon, and $A L K$ is the total alkalinity, and where salinity changes have been neglected. Both $D I C$ and $A L K$ are directly influenced by biological activity, while $D I C$ is additionally influenced by air-sea exchange of $\mathrm{CO}_{2}$.

To proceed, we first assume that the effect of changes in alkalinity on $\mathrm{pCO}_{2}$ is negligible relative to changes in DIC. We thus assume that the effect of changes on alkalinity due to biogenic $\mathrm{CaCO}_{3}$ formation and $\mathrm{NO}_{3}$ consumption and production cancel each other out. This assumption allows us to estimate that DIC will covary with temperature according to

$$
\frac{d D I C}{d T}=\frac{\left(\left(\frac{d \ln P_{\mathrm{CO}_{2}}}{d T}\right)_{O b s}-\left(\frac{\partial \ln P_{\mathrm{CO}_{2}}}{\partial T}\right)_{D I C, A L K}\right)}{\left(\frac{\partial \ln P_{\mathrm{CO}_{2}}}{\partial D I C}\right)_{T, A L K}}
$$

where $\left(d \ln P_{\mathrm{CO}_{2}} / d T\right)_{\text {obs }}$ is the observed covariation of $\mathrm{CO}_{2}$ partial pressure with temperature. The numerator on the right-hand side is the contribution to $\left(d \ln P_{\mathrm{CO}_{2}} / d\right)_{\mathrm{obs}}$ due to biology and due to air-sea exchange of $\mathrm{CO}_{2}$.

We next assume that the seasonal changes in DIC caused by air-sea exchange of $\mathrm{CO}_{2}$ are negligible relative to those caused by biology. We further assume that dissolved $\mathrm{O}_{2}$ in the mixed layer remains in equilibrium with atmospheric $\mathrm{O}_{2}$. The results from the mixed-layer model described in section 2 indicate that both these assumptions are quite reasonable. Together, these assumptions allow us to tie the biologically driven $\mathrm{O}_{2}$ flux at a single location to the rate of change of heat storage and the change of DIC with temperature at that location

$$
F_{\mathrm{O}_{2}}=-R_{\mathrm{O}_{2}: c} \frac{d D I C}{d T} \frac{\dot{\phi}}{C_{p}}
$$

where $R_{O 2: C}$ is the $\mathrm{O}_{2}: C$ Redfield ratio, and where $d D I C / d T$ is calculated from Eq. (21). A formal derivation of Eq. (22) is presented in Appendix B. Equation (22) automatically yields oxygen fluxes which are locally balanced over a year. Note that, by scaling to the heat flux, which is a vertically integrated term, Equation (22) accounts for $\mathrm{O}_{2}$ production throughout the upper water column.

The thermodynamic derivatives in Equation (21) are calculated using the algorithms and thermodynamic data from Peng et al. [1987]. The thermodynamic derivatives are assumed to be constant at each grid location using values appropriate for the annual-mean temperature. The thermodynamic derivatives are calculated assuming that surface waters contain a constant $\mathrm{CO}_{2}$ partial pressure of $340 \mu \mathrm{atm}$ of $\mathrm{CO}_{2}$, a constant alkalinity of 2350

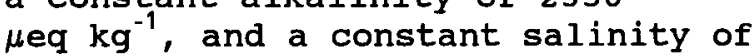
34.5 per mil. In fact, the derivatives are not very sensitive to these assumptions. For $\left(d \ln P_{C_{2}} / d T\right)_{o b s}$, we note that this term is largely independent of season within certain latitude 
bands. We thus assume the constant value observed for a given latitude band at different times of the year is equal to the value which would be observed for a given site repeatedly occupied over a year. We take a value for $\left(d l n P_{\mathrm{CO}_{2}} / d T\right)_{\mathrm{obs}}$ of $-0.012{ }^{\circ} \mathrm{C}^{-1}$ south of $37^{\circ} \mathrm{S}$, a value of $0.020{ }^{\circ} \mathrm{C}^{-1}$ from $37^{\circ} \mathrm{S}$ to $37^{\circ} \mathrm{N}$, and a value of $-0.02{ }^{\circ} \mathrm{C}^{-1}$ north of $37^{\circ} \mathrm{N}$. These values are suggested by recent work of Takahashi et al. [1991]. For $R_{02: c}$ we take the standard Redfield ratio of $138 / 106$. The computed source fields for $\mathrm{O}_{2}$, averaged over six latitude bands, are shown in Figure 13.

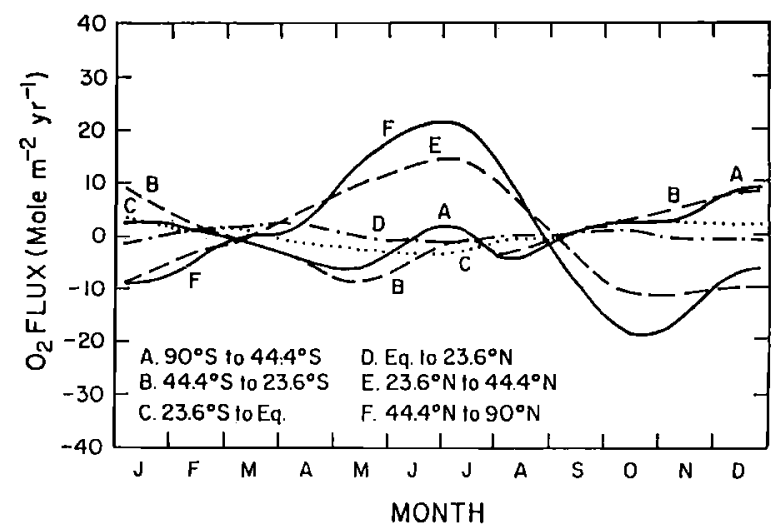

Fig. 13. Seasonal sources and sinks of $\mathrm{O}_{2}$ due to air-sea exchange driven by marine biosphere, shown as averages over six latitude bands. Sources are based on the "second" model (see text). Fluxes are expressed per unit ocean area.

\subsection{Predicted Seasonal Variations}

The estimates of the seasonally varying source fields are now inserted into the two-dimensional transport model described above in order to calculate concentration changes in the atmosphere. Figure $14 \mathrm{a}$ and $14 \mathrm{~b}$ show the components of the seasonally varying surface concentrations for $\mathrm{O}_{2} / \mathrm{N}_{2}$ at $33^{\circ} \mathrm{N}$ and $58^{\circ} \mathrm{N}$. The amplitudes of the

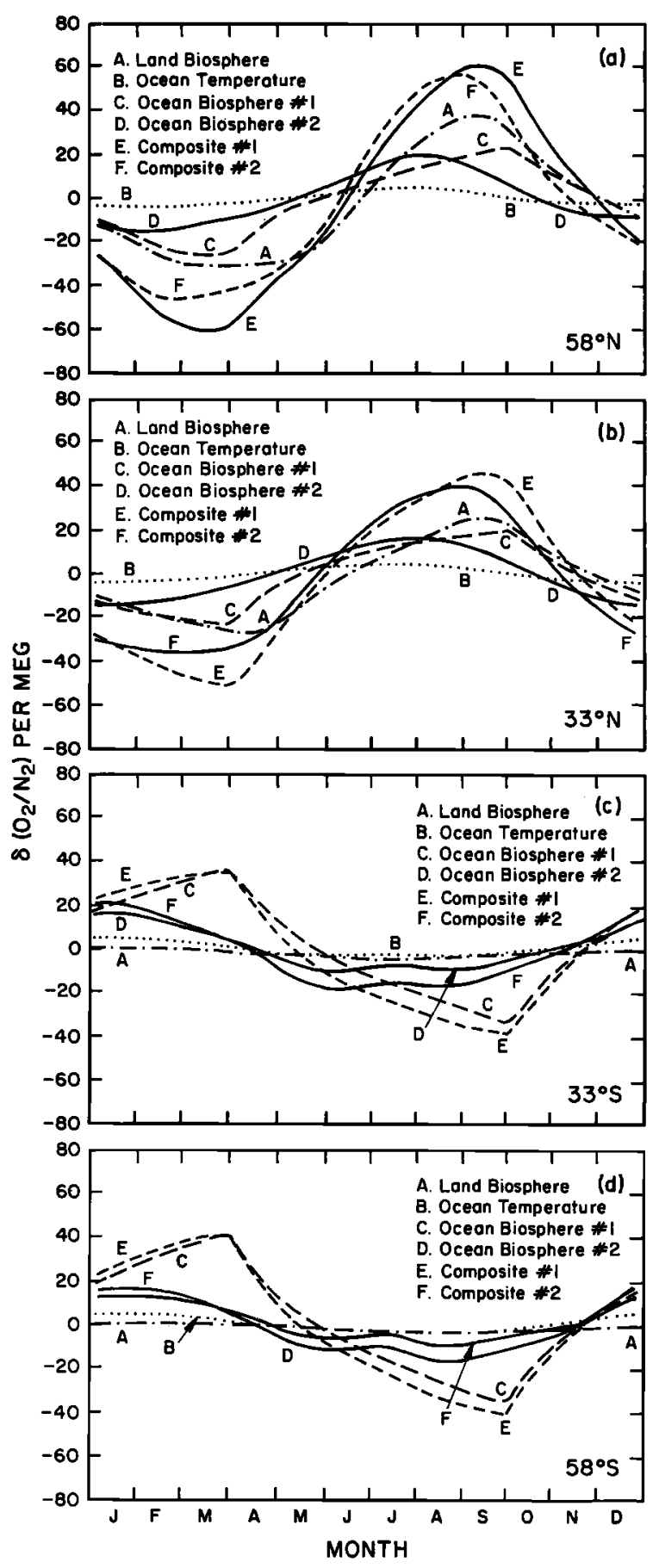

Fig. 14. Predicted components of the seasonal variations in atmospheric $\mathrm{O}_{2} / \mathrm{N}_{2}$ ratio. "Composite 1" and "Composite 2" refer to the total variations formed from the sum of all components using "first" and "second" ocean models, respectively, (a) $58^{\circ} \mathrm{N}$, (b) $33^{\circ} \mathrm{N}$, (c) $33^{\circ} \mathrm{s}$, and (d) $58^{\circ} \mathrm{S}$. 
seasonal variations driven by marine biota, as predicted by the first ocean model, which assumes global average net $o_{2}$ production of 7 moles $\mathrm{m}^{-2} \mathrm{yr}^{-1}$, are 40 per meg at $33^{\circ} \mathrm{N}$ and 50 per meg at $58^{\circ} \mathrm{N}$, peakto-peak. These amplitudes are nearly as large as those driven by terrestrial biota which are 50 per meg at $33^{\circ} \mathrm{N}$ and 70 per meg at $58^{\circ} \mathrm{N}$. The amplitudes of the seasonal variations driven by marine biota, as predicted by the second ocean model which is based on the gradient of mixed layer $\mathrm{pCO}_{2}$ with temperature, are 36 and 38 per meg peak-to-peak at $33^{\circ} \mathrm{N}$ and $58^{\circ} \mathrm{N}$, respectively. These amplitudes are slightly smalier than those predicted from the first model. The amplitudes of the variations in $\mathrm{O}_{2} / \mathrm{N}_{2}$ from ocean temperature changes are quite small ( 9 per meg peak-topeak at both $33^{\circ} \mathrm{N}$ and $58^{\circ} \mathrm{N}$ ).

Figures $14 \mathrm{C}$ and $14 \mathrm{~d}$ show the components of the seasonally varying concentration fields at $33^{\circ} \mathrm{S}$ and $58^{\circ} \mathrm{s}$. In the southern

hemisphere, the seasonal variations are dominated by fluxes driven by marine biota, with only small contributions from terrestrial biota and from ocean temperature. Here the two models of the fluxes from marine biota yield very different predictions of the atmospheric signals. The seasonal component from the first model has a peak-to-peak amplitude of about 70 per meg with a maximum in late March, while the seasonal component of the second model is quite irregular with an amplitude of only 20 per meg peak-to-peak with the maximum occurring in January. The large discrepancies between these two model predictions underscores how little is really known about air-sea oxygen fluxes at this time, particularly in the southern hemisphere.

Figures $15 \mathrm{a}$ and $15 \mathrm{~b}$ show the components of the seasonally varying concentration fields at $3^{\circ} \mathrm{N}$ and $3^{\circ} \mathrm{S}$. The seasonal $\mathrm{O}_{2}$ changes

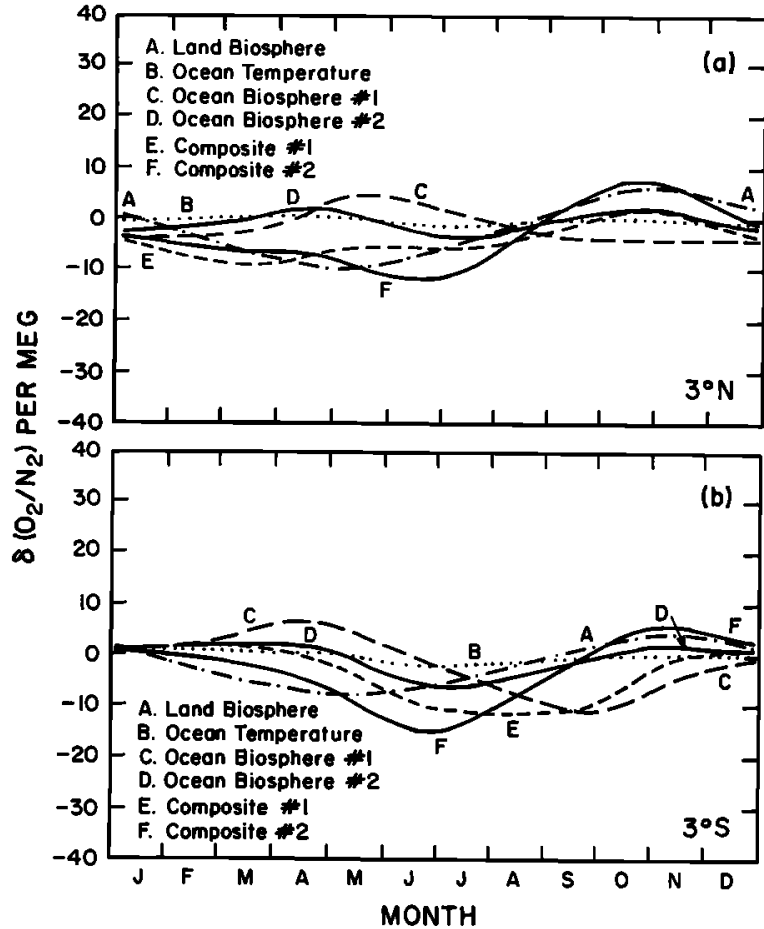

Fig. 15. Same as Figure 14 except for the latitudes (a) $3^{\circ} \mathrm{N}$ and (b) $3^{\circ} \mathrm{S}$.

predicted in the tropics are largely dependent on atmospheric transport from poleward latitudes because the inferred seasonal sources in the tropics are relatively weak (see Figures 9, 10, 12 , and 13). The variations from sources in the northern and southern hemispheres tend to cancel each other out in the tropics because the sources in the two hemispheres are diametrically out of phase with each other.

\section{APPLICATIONS OF ATMOSPHERIC $\mathrm{O}_{2}$ MEASUREMENTS}

We now return to a general discussion of the relationship between atmospheric $\mathrm{O}_{2}$ measurements and specific scientific questions: (1) What is the magnitude and distribution of new production in the ocean. (2) What is the net source or sink of $\mathrm{CO}_{2}$ from terrestrial temperate ecosystems? As summarized in Table 2, these 


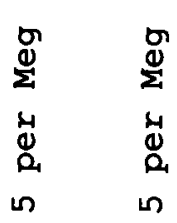

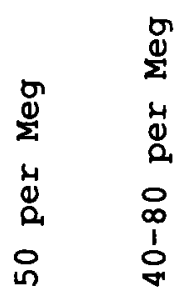

$\begin{array}{ll}0 & 0 \\ 0 & 0 \\ 2 & 0 \\ 04 & 0 \\ 0 & 0 \\ 0 & 0 \\ 0 & 0 \\ 0 & 0 \\ 0 & 0\end{array}$
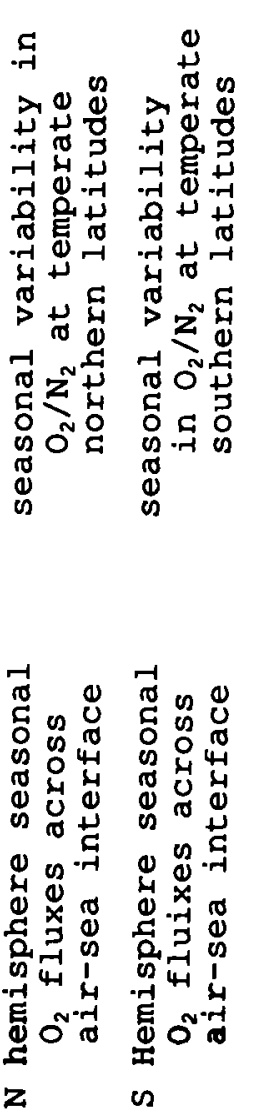

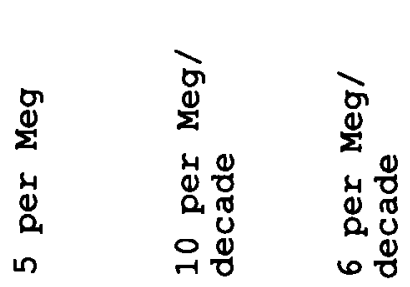

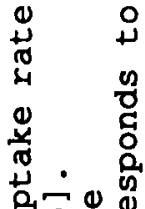
육

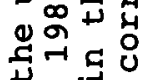

4엉 宅

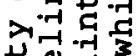

类

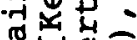

岁出荠

के

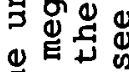

के केष्प कू के लू

$F_{4}$

इU भणंड भणंड

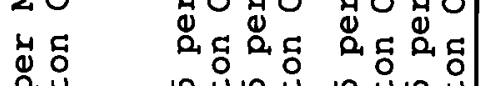

ते

a $r$.

면

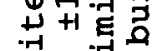

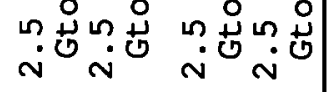

.

过

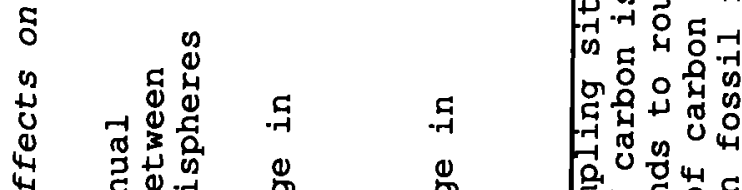

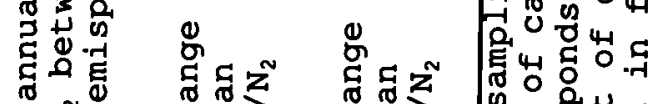

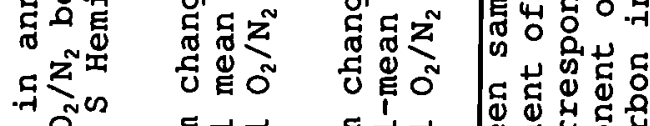

芹先宗

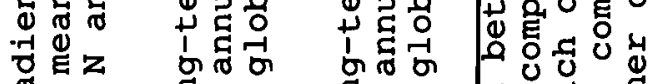

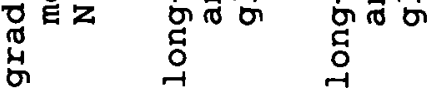

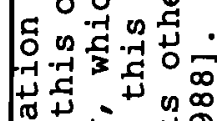

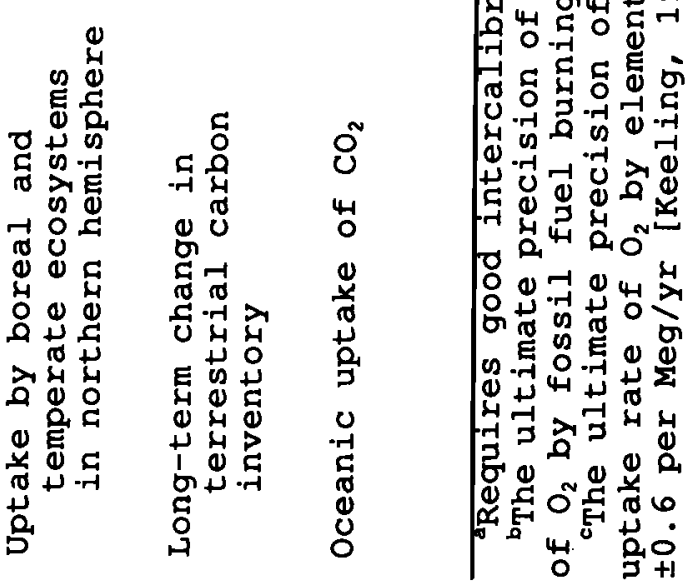


questions can be addressed by measurements of three features of the atmospheric $\mathrm{O}_{2}$ distribution: seasonal variations, long-term changes in atmospheric $\mathrm{O}_{2}$ inventory, and the north-south gradient in annual-mean concentrations.

\subsection{Constraining Oceanic New Production}

The calculations in the previous section suggest that seasonal variations of the order of 50 to 100 per meg should be a ubiquitous feature of the Earth's atmosphere at middle and high latitudes. The variations in the southern hemisphere are predominantly caused by biologically mediated air-sea exchange of $\mathrm{O}_{2} ;$ the variations in the northern hemisphere result mainly from comparable contributions from terrestrial exchanges and air-sea exchanges. our model calculations suggest that variations in the tropics will be smaller, and away from the tropics the amplitude of the seasonal variations should vary quite smoothly with latitude. Thus the dominant features of the atmospheric variability could be resolved with samples collected at a modest number of well chosen sampling sites.

The amplitude of the seasonal cycles in $\mathrm{O}_{2} / \mathrm{N}_{2}$ contains information on rates of new production in each hemisphere. To extract this information we must also account for the effects of $\mathrm{O}_{2}$ exchanges with terrestrial ecosystems (especially in the northern hemisphere), air-sea fluxes driven by ocean temperature changes, mixing of the $\mathrm{O}_{2}$ signals throughout the atmosphere, and on the complex interplay between $\mathrm{O}_{2}$ production associated with new production and $\mathrm{O}_{2}$ removal associated the ventilation of deeper waters. We envision a strategy which would employ measurements of atmospheric $\mathrm{CO}_{2}$ and the ${ }^{13} \mathrm{C} /{ }^{12} \mathrm{C}$ ratio of atmospheric $\mathrm{CO}_{2}$ in conjunction with atmospheric transport models to distinguish the terrestrial contributions to the $\mathrm{O}_{2} / \mathrm{N}_{2}$ variations (see also Keeling and Shertz [1992]). The strategy would also employ model calculations (as above) or measurements of changes in atmospheric $\mathrm{O}_{2} / \mathrm{Ar}$ ratio to distinguish oceanic thermal contributions and would employ atmospheric transport models to invert the atmospheric data to derive large-scale estimates of the air-sea $\mathrm{O}_{2}$ fluxes induced by marine biology. Such flux estimates would place a direct constraints new production and ventilation fluxes in the upper ocean and would be an important benchmark for validating global three-dimensional ocean models incorporating realistic biological activity.

\subsection{Constraining the Net Terrestrial Carbon Sink}

Schematically, we can represent the global budget for atmospheric $\mathrm{CO}_{2}$ according to

$$
\Delta \mathrm{CO}_{2}=\mathrm{F}-\mathrm{O}+\mathrm{B}
$$

where $\Delta \mathrm{CO}_{2}$ is the annually averaged change in atmospheric $\mathrm{CO}_{2}, F$ is the source of $\mathrm{CO}_{2}$ from burning fossil fuel, $O$ is the oceanic $\mathrm{CO}_{2}$ sink, and $B$ is the net source of $\mathrm{CO}_{2}$ from terrestrial ecosystems ( $B$ can be positive or negative), all in units of moles per year. Likewise, we can represent the budget for atmospheric oxygen according to

$$
\Delta O_{2}=-\rho_{F} F-\rho_{b} B
$$

where $\Delta \mathrm{O}_{2}$ is the change in atmospheric oxygen, $F$ and $B$ are identical to the terms in Equation (23) and $\rho_{F}$ and $\rho_{B}$ represent the $\mathrm{O}_{2}: \mathrm{C}$ exchange ratio for burning fossil fuels and production and destruction of terrestrial biomatter, respectively.

There is no term in the oxygen budget which is comparable to the 
term $O$ in the $\mathrm{CO}_{2}$ budget. This is because oceanic $\mathrm{CO}_{2}$ removal is presumed to occur via reaction with carbonate ion which does not involve $\mathrm{O}_{2}$. Furthermore, because the atmosphere contains 100 times as much $\mathrm{O}_{2}$ as the oceans, the longterm decrease in $O_{2}$ partial pressure is not buffered by the oceans.

For purposes of analysis, it is convenient to separate the oxygen loss from fossil fuel burning according to

$$
\rho_{F} F=F+H
$$

where $F$ represents the oxygen loss due to oxidation of carbon, and $H$ represents the oxygen loss due to oxidation of all other elements (predominantly hydrogen).

Equations (23) and (24) can be solved for the total terrestrial $\mathrm{CO}_{2}$ source:

$$
B=-\left(\Delta O_{2}+\rho_{F} F\right) / \rho_{B}
$$

Alternatively, Equations (23) through (25) can be solved to calculate the rate of $\mathrm{CO}_{2}$ uptake by the oceans:

$$
0=-\Delta \mathrm{CO}_{2}-\Delta \mathrm{O}_{2}-\mathrm{H}+(1-\rho) B
$$

The last term on the right of Equation (27) should be very small because $\rho_{B} \approx 1$.

These above relations show how measurements of $\Delta \mathrm{O}_{2}$, the long-term change in atmospheric oxygen, can constrain the major fluxes of carbon. With sufficiently accurate oxygen measurements, the approach will be limited by the uncertainties in the fossil fuel terms in Equations (26) and (27). The fossil fuel terms in Equation (27) involves smaller uncertainties than the fossil fuel terms in Equation (26) because uncertainties involved in estimating $H$ are smaller than those involved in estimating $\rho_{F} F$ [Keeling, 1988]. Thus the potential constraint on oceanic $\mathrm{CO}_{2}$ uptake is tighter than the potential constraint net biospheric $\mathrm{CO}_{2}$ source.

In formulating the budgets for atmospheric $\mathrm{O}_{2}$ and $\mathrm{CO}_{2}$ in Equations (23) and (24), we have neglected the effect of ocean ingassing or outgassing due to long-term changes in ocean temperature, fluxes due to weathering and sedimentation, and long-term uptake or release of $\mathrm{O}_{2}$ by the oceans mediated by marine biological cycles. These issues have been explored in some detail by Keeling [1988], and the effects are currently believed to be small, although more study is needed. The role of marine biota in the longterm oxygen balance of the oceans can be assessed by looking for secular changes in the preformed nutrients because any marine biological effects on atmospheric $\mathrm{O}_{2}$ should leave a signature in the preformed nutrient distribution, as mentioned in section 3 (see also Peng and Broecker [1984]).

While measurements of the longterm trend in $\mathrm{O}_{2} / \mathrm{N}_{2}$ can constrain the global net sink of $\mathrm{CO}_{2}$ from the terrestrial biosphere, comparison of the north-south gradients in atmospheric $\mathrm{O}_{2} / \mathrm{N}_{2}$ and $\mathrm{CO}_{2}$ may provide additional information on the geographical distribution of the sink. Net production (positive or negative) by the marine or terrestrial biospheres will be manifested in north-south gradients which reflect reaction stoichiometry, while inorganically mediated air-sea exchange of $\mathrm{CO}_{2}$ will produce $\mathrm{CO}_{2}$ gradients which are unaccompanied by $\mathrm{O}_{2}$ gradients. Thus, for example, complementary data on the north-south gradients in the $\mathrm{O}_{2}$ and $\mathrm{CO}_{2}$ concentrations of air can inform us about growth rates of the terrestrial biosphere in northern boreal and temperate regions and about the nature of interhemispheric transport of $\mathrm{CO}_{2}$ by ocean circulation. Our model 
calculations above included estimates of the steady state effects of both marine biological productivity and heat fluxes on the north-south oxygen gradient. Although these model results indicated that the effects are quite small, more work is needed on this subject.

The interpretation of the northsouth gradient in $\mathrm{O}_{2} / \mathrm{N}_{2}$ will ultimately be limited by uncertainty in the rate of fossil fuel burning and the rates of interhemispheric transport. At present, these combined sources of error make the prediction of the gradient from fossil fuel uncertain at the 10 to $20 \%$ per meg level. This uncertainty is magnified when evaluating the smaller nonfossil gradient in the $\mathrm{O}_{2} / \mathrm{N}_{2}$ ratio.

\section{SUMMARY AND CONCLUSIONS}

We have presented a strategy for interpreting data on the distribution of $\mathrm{O}_{2}$ in air to produce new constraints on the global carbon cycle. Data on seasonal variations in the distribution of atmospheric $\mathrm{O}_{2}$ can be interpreted, using atmospheric circulation models, to give data on air-sea $\mathrm{O}_{2}$ fluxes. The long-term decrease in the $\mathrm{O}_{2}$ concentration in air will inform us about transient carbon fluxes associated with anthropogenic perturbations. Specifically, the net conversion rate of terrestrial biomass to $\mathrm{CO}_{2}$ is determined from the difference between the total long-term $\mathrm{O}_{2}$ decrease and the (known) $\mathrm{O}_{2}$ consumption rate associated with the burning of fossil fuels. Also, the rate of $\mathrm{CO}_{2}$ dissolution in the oceans directly related to the difference between the long-term $\mathrm{O}_{2}$ decrease and the long-term atmospheric $\mathrm{CO}_{2}$ increase. Finally, the north-south $\mathrm{O}_{2}$ gradient provides a constraint on the distributions of net carbon exchange by marine and terrestrial ecosystems and by fossil fuel burning.

\section{APPENDIX A}

our starting point for estimating $\mathrm{O}_{2}$ new production and ventilation fluxes is the three-dimensional model of Najjar et al. [1992]. We use a version of the model which assumes that $80 \%$ of the organic matter exported from the euphotic zone is exported as dissolved or suspended matter and $20 \%$ is exported as particulates. The model yields estimates of the annual-mean export flux of organic matter from the euphotic zone, as well as the net air-sea $O_{2}$ flux. We scale the carbon export flux by a standard Redfield ratio of $138 / 106$ to yield an estimates of the new $\mathrm{O}_{2}$ production. We zonally average these new production and ventilation fields to yield zonally averaged fields in $4.5^{\circ}$ latitude bands. The model yields a value for the globally averaged export flux of organic carbon of 1.9 mole $C \mathrm{~m}^{-2} \mathrm{yr}^{-1}$ and thus for the globally averaged new $\mathrm{O}_{2}$ production of 2.5 mole $\mathrm{m}^{-2} \mathrm{yr}^{-1}$.

The three dimensional model accounts for the carbon fluxes associated with nutrients recycled from the main thermocline and the deep ocean, but because the model is nonseasonal, it neglects the component associated with nutrients recycled from the seasonal thermocline. We assume that we can account for this neglected component by adding an additional 4.5 mole $\mathrm{m}^{-2}$ of new $\mathrm{O}_{2}$ production uniformly over the whole ocean surface. This revised field yields a total of 7 mole $\mathrm{O}_{2} \mathrm{~m}^{-2} \mathrm{yr}^{-1}$ for globally averaged new $\mathrm{O}_{2}$ production. The value of 4.5 mole $\mathrm{m}^{2}$ for the neglected component was selected by noting that "total" new production of $\mathrm{O}_{2}$ in oligotrophic waters near Bermuda is about 5 moles $\mathrm{m}^{-2} \mathrm{yr}^{-1}$ [Jenkins and Goldman, 1985] and that the global average "total" new $\mathrm{O}_{2}$ production can be expected to be somewhat larger than for oligotrophic waters $(\mathrm{e} . \mathrm{g}$. around 7 mole 
$\left.\mathrm{m}^{-2} \mathrm{yr}^{-1}\right)$. We use this revised field for new $\mathrm{O}_{2}$ production as a basis for computing seasonal airsea $\mathrm{O}_{2}$ fluxes, as described in section 3.4 .

In order to derive an estimate of the ventilation fluxes, we first separate the field for the air-sea $\mathrm{O}_{2}$ flux into thermal and biological components, as described in section 3.2. We derive the appropriate ventilation flux field by simply subtracting the field for biological air-sea flux from the field for "total" new $\mathrm{O}_{2}$ production, derived above.

\section{APPENDIX B}

We present here a more complete derivation of Equations (19) and (22). We start by defining preformed DIC as follows:

$$
D I C_{\text {pre }}=D I C-A O U / R_{\mathrm{O}_{2}: C}
$$

where $R_{\mathrm{O}_{2}: c}$ is the "Redfield" $\mathrm{O}_{2}: \mathrm{C}$ ratio. Preformed DIC is a conservative tracer which is unchanged by photosynthesis and respiration within the water mass. We assume that oxygen is always at equilibrium with the atmosphere within the mixed layer, or, in other words that AOU is zero in the mixed layer. This means that there is no distinction between DIC and preformed DIC within the mixed layer.

We next assume that DIC is linearly related to temperature within the mixed layer throughout the year. This means that the tracer $\psi$, which we define as

$$
\psi=D I C_{\text {pre }}-\left(\frac{d D I C}{d T}\right) \Delta T
$$

is constant as a function of time in the mixed layer. In Equation (29), $\Delta T$ is the deviation of the temperature from the annual mean and $(d D I C / d T)$ is the slope of the observed relation between DIC and temperature.

Now, since both $\Delta T$ and $D I C_{p r e}$ are conservative tracers, it follows that $\Psi$ is also a conservative tracer. Furthermore, since $\psi$ is constant as a function of time within the mixed layer it follows that $\psi$ should also be constant and independent of time throughout the water column. This follows because the magnitude of $\psi$ throughout the water column must eventually approach, through vertical mixing, the constant value that is maintained in the mixed layer. An exception to this would be a situation where a different value of $\psi$ was horizontally advected from a different region of the sea surface. This situation is not likely to be very significant for our purposes here because (1) we actually only require that $\psi$ be constant up to the depth over which seasonality in temperature, carbon, and oxygen is significant, and (2) the observations of Takahashi et al. [1991] indicate that a single linear relation with temperature can account quite well for both spatial and temporal variations in $\mathrm{CO}_{2}$ partial pressure, from which it follows that horizontal gradients in $\psi$ should, in general, be quite small.

From the constancy of $\psi$ within the water column we have

$$
\frac{\partial}{\partial t} \int \Psi d z=0
$$

where the integral is taken from the surface to the depth over which seasonality is significant. By combining Equations (28) and (29), the full expression for $\psi$ can be written

$$
\begin{aligned}
& \Psi=D I C+\frac{1}{R_{O_{2}: C}}\left(\left[O_{2}\right]-\left[O_{2}\right]_{e q}^{(0)}\right) \\
& -\frac{1}{R_{O_{2}: C}}\left(\frac{d\left[O_{2}\right]_{e q}}{d T}\right)^{(0)} \Delta T-\left(\frac{d D I C}{d T}\right) \Delta T
\end{aligned}
$$


In Equation (31) we have made explicit the definition of $A O U$ and have linearized the solubilitytemperature relation for $\mathrm{O}_{2}$. Now, the first two terms on the right-hand side of Equation (31) together define a conservative tracer. This tracer can only be changed by air-sea exchange of $\mathrm{O}_{2}$ or $\mathrm{CO}_{2}$ because biological transformations yield compensating changes in DIC and $\left[\mathrm{O}_{2}\right]$. Furthermore, in our model we assume that the airsea exchange flux of $\mathrm{CO}_{2}$ is negligible compared to that of $\mathrm{O}_{2}$. It follows therefore that

$$
\frac{\partial}{\partial t} \int\left(D I C+\frac{\left[O_{2}\right]}{R_{\mathrm{O}_{2} C}}\right) d z=-\frac{F_{\mathrm{O}_{2}}}{R_{\mathrm{O}_{2}: C}}
$$

where $F_{O_{2}}$ is the net sea-to-air flux of $\mathrm{O}_{2}$. Finally, substituting Equation (31) into Equation (30), and using Equation (32), we have

$$
F_{O_{2}}=-\frac{d\left[O_{2}\right]_{\theta q}}{d T} \frac{\dot{Q}}{C_{p}}-R_{O_{2}: c}\left(\frac{d D I C}{d T}\right) \frac{\dot{Q}}{C_{P}}
$$

where the rate of change of heat storage $\dot{Q}$ is given by

$$
\dot{\phi}=C_{p} \frac{\partial}{\partial t} \int \Delta T d z
$$

where $C_{F}$ is the heat capacity of seawater.

Equation (33) is the desired result. The first term on the right-hand side of Equation (33) is the $\mathrm{O}_{2}$ flux owing to seasonal temperature changes while the second term on the right-hand side of Equation (33) is the $\mathrm{O}_{2}$ flux owing to biological activity.

ACKNOWLEDGMENTS. We are grateful to steven Worley for assistance in obtaining the storage data from the archives, David Erickson, Sasha Madronich, Jorge Sarmiento, and an anonymous reviewer for helpful comments, and to Trinh Dean for help in preparing the document. This work was supported by the National science Foundation under grants ATM-8720377 and ATM-8917749; additional support for $R$. Keeling was provided by the Advanced study Program at NCAR.

\section{REFERENCES}

Bloom, A. J., R. M. Caldwell, J. Finazzo, R. L. Warner, and $J$. Weissbart, oxygen and carbon dioxide fluxes from barley shoots depend on nitrate assimilation, Plant Physiol., 91, 352-356, 1989. Bolin, B., and C. D. Keeling, Large-scale atmospheric mixing as deduced from the seasonal and meridional variations of carbon dioxide, J. Geophys. Res., 68, 3899-3920, 1963 .

Bolin, B. The carbon cycle, in Scope 21, The Major Biogeochemical Cycles and Their Interactions, edited by B. Bolin and R. B. Cook, pp. 41-45, 1983 .

Broecker, W. S., and T. - H. Peng, Gas exchange rates between air and sea, Tellus, 26, 21-35, 1974.

Broecker, W. S., and T.-H. Peng, Tracers in the Sea, Lamont-Doherty Geological observatory, Palisades, N. Y., 1982 .

Broecker, W. S., T. Takahashi, and T. Takahashi, Sources and flow patterns of deep-ocean waters as deduced from potential temperature, salinity, and initial phosphate concentration, $\mathrm{J}$. Geophys. Res., 90,6925-6939, 1985.

Detwiler, R. P., and C. A. S. Hall, Tropical forests and the global carbon cycle, Science, 239, 42-47, 1988 .

Fung, I., K. Prentice, E. Matthews, J. Lerner, and G. Russel, Threedimensional tracer model study of atmospheric $\mathrm{CO}_{2}$ : Response to seasonal exchange with the terrestrial biosphere, J. Geophys. Res. 88, 1281-1294, 1983 . 
Glover, D. M., and P. G. Brewer, Estimates of wintertime mixed layer nutrient concentrations in the North Atlantic, Deep Sea Res., $35,1525-1546,1988$.

Jähne, B., G. Heinz, and W. Dietrich, Measurement of the diffusion coefficients of sparingly soluble gases in water, J. Geophys. Res., 92, 10767-10776, 1987.

Jenkins, W. J., and J. C. Goldman, Seasonal oxygen cycling and primary production in the sargasso Sea, J. Mar. Res., 43, 465-491, 1985.

Kawase, M., and J. L. Sarmiento, Nutrients in the Atlantic thermocline, J. Geophys. Res., 90, 8961-8979, 1985.

Keeling, R. F., Development of an interferometric oxygen analyzer for precise measurement of the atmospheric $\mathrm{O}_{2}$ mole fraction, Doctoral thesis, 178 pp, Harvard Univ., Cambridge, Mass., 1988a.

Keeling, R. F., Measuring correlations in atmospheric $\mathrm{O}_{2}$ and $\mathrm{CO}_{2}$ mole fractions: A preliminary study in urban air, J.Atmos. Chem. , 7, 153-176, 1988b.

Keeling, R. F., and S. R. Shertz, Seasonal and interannual variations in atmospheric oxygen and implications for the global carbon cycle, Nature, 358, 1992. Najjar, G. R., Simulations of the phosphorous and oxygen cycles in the world ocean using a general circulation model, Ph.D. thesis, Princeton Univ., Princeton, N. J., 1990.

Najjar, G. R., J. L. Sarmiento, and J. R. Toggweiler, Downward transport and fate of organic matter in the ocean: simulations with a general circulation model, Global Biogeochem. Cycles, 6, 4576,1992 .

Pearman, G. I., and P. Hyson, Activities of the global biosphere as reflected in atmospheric $\mathrm{CO}_{2}$ records, J. Geophys. Res. 85, $4468-4474$, 1980 .
Peng, T. -H., and W. S. Broecker, Ocean life cycles and the atmospheric $\mathrm{CO}_{2}$ content, $\mathrm{J}$. Geophys. Res., 89, 8170-8180, 1984 .

Peng, T.-H., T. Takahashi, and $\mathrm{W}$. S. Broecker, Seasonal variability of carbon dioxide, nutrients, and oxygen in the northern North Atlantic surface water: Observations and a model, Tellus Ser. B, 39, 439-458, 1987.

Plumb, R. A., and J. D. Mahlman, Zonally averaged transport characteristics of the GFDL general circulation/transport model, J.Atmos. Sci., 44, 298$327,1987$.

Redfield, A. B., B. H. Ketchum, and F. A. Richards, The influence of organisms of the composition of seawater, in The Sea, vol. 2, edited by M. N. Hill, pp. 26-77, Wiley Interscience, New York, 1963.

Rotty, R. M., Distribution and changes in industrial carbon dioxide production, J. Geophys. Res., 88, 1301-1308, 1983 .

Rotty, R. M. , Estimates of seasonal variations in fossil fuel $\mathrm{CO}_{2}$ emissions, Tellus Ser. B, 39, 184202,1987 .

Samuels, B. L., and M. Cox, Data set atlas for oceanographic modelling, ocean Modelling, 75, 13,1987 .

Shulenberger, E., and J. L. Reid, The pacific shallow oxygen maximum, deep chlorophyll maximum, and primary productivity, reconsidered, Deep Sea Res., Part A, 28, 901-919, 1981.

Takahashi, T., J. Goddard, D. W. Chipman, S. C. Sutherland, and G. Mathieu, Assessment of carbon dioxide sink/source in the North Pacific Ocean: Seasonal and geographic variability, 1984-1989, Final Tech. Rep. for DOE contract 19X-SC428C, Lamont-Doherty Geological observatory, Palisades, N. Y., 1991.

Tans, P. P., T. J. Conway, and T. 
Nakazawa, Latitudinal distribution of the sources and sinks of atmospheric carbon dioxide derived from surface observations and an atmospheric transport model, $\mathrm{J}$. Geophys. Res., 94, 5151-5172, 1989.

Tans, P. P, I. Y. Fung, and T. Takahashi, Observational constraints on the atmospheric $\mathrm{CO}_{2}$ budget, science, 247, 1431-1438, 1990.

Toggweiler, J. R., K. Dixon, and K. Bryan, Simulations of radiocarbon in a coarse-resolution world ocean model, 1, steady state prebomb distributions, J. Geophys. Res.. 94, 8217-8242, 1989 .

Weiss, R. F., The solubility of nitrogen, oxygen and argon in water and seawater, Deep Sea Res.. 17, 721-735, 1970 .
Wise, D. L., and G. Houghton, The diffusion coefficients of ten slightly soluble gases in water at $10-60^{\circ} \mathrm{C}$, Chem. Eng. Sci., 21, 999$1010,1966$.

M. L. Bender, Graduate School of Oceanography, University of Rhode Island, Kingston, RI 02881.

R. F. Keeling and R. G. Najjar, National Center for Atmospheric Research, Boulder, CO 80307.

P. P. Tans, climate Monitoring and Diagnostics Laboratory, National Oceanic and Atmospheric Administration, Boulder, co 80303 .

(Received March 23, 1992;

revised November 6, 1992 ;

accepted November 16, 1992.) 